\section{1}

\section{2}

\title{
Meiotic DNA breaks activate a streamlined phospho- signaling response that largely avoids protein level changes
}

\author{
Funda M. Kar ${ }^{1}$, Christine Vogel ${ }^{1}$, Andreas Hochwagen ${ }^{1}$ \\ 1 New York University, Department of Biology, New York, USA \\ Corresponding author: andi@nyu.edu
}

\section{Abstract}

Meiotic cells introduce a large number of programmed DNA breaks into their genome to stimulate meiotic recombination and ensure controlled chromosome inheritance and fertility. An intricate checkpoint network involving key kinases and phosphatases coordinates the repair of these DNA breaks during meiosis, but the precise DNA break-dependent phosphorylation targets remain poorly understood. It is also unknown whether meiotic DNA breaks change gene expression akin to the canonical DNA-damage response. To address these questions, we analyzed the meiotic DNA break response in Saccharomyces cerevisiae using multiple systems-level approaches. We identified 332 DNA break-dependent phosphorylation sites, vastly expanding the number of known DNA break-dependent phosphorylation events during meiotic prophase. Only about half of these events occurred in recognition motifs for the known meiotic checkpoint kinases Mec1 (ATR), Tel1 (ATM) and Mek1 (CHK2), suggesting that additional kinases contribute to the meiotic DNA break response. Surprisingly, the numerous changes in phosphorylation were accompanied by very few changes in protein levels despite a clearly detectable transcriptional response. To explain this dichotomy, we show that meiotic entry lowers the expression baseline of many mRNAs enough so that subsequent breakdependent mRNA production has no measurable effects on the largely stable proteome.

\section{Introduction}

Homologous recombination during meiosis is initiated by programmed DNA breaks created by the conserved topoisomerase-like protein Spo11 (Bergerat et al., 1997; Keeney et al., 1997). By stimulating crossover formation, these DNA breaks promote genetic diversity in the offspring and, in many organisms, are essential for faithful segregation of chromosomes (Lam \& Keeney, 2015). Accordingly, failure to produce DNA breaks leads to infertility in yeast and mammals (Baudat et al., 2000; Klapholz et al., 1985; Romanienko \& Camerini-Otero, 2000). 
However, the large number of DNA breaks also represents an inherent hazard for genome instability. To protect the genome, a complex signaling network coordinates meiotic processes in response to DNA break formation and prevents inappropriate meiotic progression when break repair is delayed or defective (MacQueen \& Hochwagen, 2011; Subramanian \& Hochwagen, 2014).

We are only beginning to understand the signaling pathways that connect meiotic DNA break formation to DNA repair and other meiotic processes. Available data indicate a prominent role for the canonical DNA-damage sensor kinases ATR and ATM, although the extent to which the two kinases are linked to the control of meiotic processes may vary between organisms (Kar \& Hochwagen, 2021). In the budding yeast, Saccharomyces cerevisiae, the homologues of ATR and ATM, Mec1 and Tel1, respectively, and the downstream CHK2-like effector kinase Mek1 regulate a large number of meiotic processes, including DNA break formation and repair, chromosome pairing, and meiotic cell-cycle progression (Kar \& Hochwagen, 2021). Targeted studies in yeast have identified relevant DNA break-dependent phosphorylation events for several of these processes, including control of break levels (Carballo et al., 2013), suppression of sister-chromatid recombination (Callender et al., 2016; Carballo et al., 2008; Niu et al., 2009), crossover formation (Chen et al., 2015; He et al., 2020; Woo et al., 2020), centromere uncoupling (Falk et al., 2010), and control of meiotic cell-cycle progression (Chen et al., 2018; Penedos et al., 2015). Targeted mutagenesis based on known kinase motifs mapped additional, functionally important break-dependent phosphorylation sites (Bartrand et al., 2006; CartagenaLirola et al., 2006; Serrentino et al., 2013), and a number of DNA break-dependent, site-specific phosphorylation events of unknown functional significance have been identified (Kniewel et al., 2017; Shroff et al., 2004; Suhandynata et al., 2016). However, available data (Garcia et al., 2015; MacQueen \& Roeder, 2009; Mohibullah \& Keeney, 2017) indicates that our understanding of the signaling response to meiotic DNA break formation is far from complete.

One little-explored aspect of the meiotic DNA break response is the relationship between the signaling pathways discussed above and changes in gene expression. The canonical DNAdamage response in vegetative yeast cells involves a well-defined transcriptional response that is signaled through Mec1/Tel1-dependent activation of the effector kinases Rad53 and Dun1 (Jaehnig et al., 2013). These kinases activate a core set of DNA-damage response genes, including genes coding for DNA-repair factors and regulators of nucleotide abundance. Rad53 activity is attenuated, but not absent, during meiotic DNA break formation (Cartagena-Lirola et al., 2008), posing the question as to the role of transcriptome and proteome remodeling during this step in meiosis.

To address these questions, we conducted a systems-level analysis to capture the cellular response to meiotic DNA breaks with respect to phospho-proteomic, proteomic, and transcriptomic changes. We identified hundreds of novel DNA break-dependent phosphorylation sites, highlighting the breadth of the signaling response to meiotic DNA breaks. Surprisingly, we observed a transcriptional response to DNA breaks that did not lead to detectable changes in the proteome. We explain this discrepancy by the differences in regulation of protein and mRNA abundance during meiotic prophase. 


\section{Results}

\section{Experimental setup to measure multiple aspects of the meiotic DNA break} response

To capture the meiotic DNA break response from multiple angles, we performed transcriptomic, proteomic, and phospho-proteomic analyses in S. cerevisiae (Figure 1A). We compared DNA break-proficient cells carrying a functional SPO11 gene with catalytic spo11-YF mutants, which cannot form DNA breaks (Bergerat et al., 1997). To ensure the most robust and stringent analysis possible, we implemented several additional experimental features. First, to avoid differences in meiotic state between DNA break-competent SPO11 cells, which delay in prophase compared to spo11 mutants (Keeney, 2001), we removed the mid-meiosis transcription factor Ndt80 genetically from both strains. NDT80 deletion synchronizes both cultures prior to the exit from meiotic prophase (Xu et al., 1995), and thus eliminates cell-cycle differences, which create a well-known false-positive signal when studying the cellular response to DNA damage (Gasch et al., 2001; Suhandynata et al., 2016). Second, to increase recovery of DNA break-dependent phosphorylation events, we used a pph $3 \Delta$ mutation to inactivate protein phosphatase 4 (PP4), one of the major phosphatases responsible for erasing Mec1/Tel1dependent phosphorylation marks (Falk et al., 2010; Hustedt et al., 2015; Keogh et al., 2006). Finally, to ensure reproducibility, proteomics and phospho-proteomics samples were collected from three independent biological replicates and analyzed by two complementary mass spectrometry techniques to maximize recovery of phosphosites. We used flow cytometric analysis of DNA replication as a proxy for meiotic synchronization to show that meiotic cultures completed $S$ phase with similar kinetics within each set of biological replicates (Supplemental Figure 1).

We quantified tryptic peptides before and after phospho-peptide enrichment to map DNA break-dependent changes in protein abundance and protein phosphorylation, respectively (Figure 1A). We used both Data-Dependent Acquisition (DDA) and Data-Independent Acquisition (DIA) to identify and quantify phosphorylation sites. DDA is the traditional method but is semi-stochastic as it only identifies the most abundant peptides. This filter biases the data towards high-abundance peptides and introduces variation in identified peptides between runs (Domon \& Aebersold, 2010; Michalski et al., 2011). DIA overcomes this problem by cofragmenting all of the peptides in pre-defined mass/charge windows. The resulting fragmentation spectra are highly complex and require more advanced algorithms and spectral libraries to resolve peptide sequences (Schubert et al., 2015), but DIA is able to achieve greater reproducibility and quantitative sensitivity than DDA (Bruderer et al., 2017; Selevsek et al., 2015), in particular for phosphoproteomics (Bekker-Jensen et al., 2020; Kitata et al., 2021). We designed a workflow that includes both methods to take advantage of their unique strengths. 
We found high reproducibility across all three biological replicates for both the DDA and DIA proteomic analysis, and both methods efficiently recovered DNA break-dependent phosphorylation sites. We observed some loss of phosphorylation events in replicate 1, either during sample preparation or because of biological variability, as indicated by the narrow distribution phosphopeptide intensity differences between SPO11 and spo11-YF cells in both the DDA and DIA analysis (Supplemental Figure 2A,C). Inspection of DNA content profiles showed that cultures from replicate 1 replicated their DNA slightly faster (Supplemental Figure 1), which may have resulted in longer prophase residence time, and led to loss of phosphorylation on some sites. This loss resulted in lower correlation of this replicate with the other replicates when examining all identified sites (Supplemental Figure 2B,D). However, the correlation with the other replicates was strong when considering only phospho-sites that were likely true-positive identifications, i.e. with an increased intensity in SPO11 samples, suggesting this replicate produced meaningful data (Supplemental Figure 3). In addition to this, replicate 1 successfully reported previously characterized DNA break-dependent phosphorylation events like Zip1 S75 and Hed1 T40 (Callender et al., 2016; Falk et al., 2010), further confirming its validity. Therefore, we chose to retain the data from all three replicates. To ensure high-quality data, we removed phosphosite identifications with more than three values missing from the six measurements of DNA break-dependence.

We used two different approaches to establish the phospho-sites affected by DNA break formation (Figure 1B). First, we extracted phospho-sites detected in both SPO11 and spo11-YF samples in at least three of the six samples and determined relative enrichment in SPO11 versus spo11-YF. This analysis classified 40 and 157 phosphorylation sites as significantly enriched in the presence of meiotic DNA breaks (adjusted p-value cutoff 0.1 ) in the DDA and DIA data, respectively (Figure 2A,B). While these phosphorylation events are induced by DNA breaks, their presence in spo11-YF samples suggests that they can occur independently of meiotic DNA breaks as well.

Second, we conducted a presence/absence analysis to also include phosphosites that are never detected in spo11-YF samples, i.e. phosphosites that are likely fully dependent on meiotic DNA break formation (Figure 1B). This analysis revealed another 118 and 111 sites as phosphorylated only and always in presence of meiotic DNA breaks in the DDA and DIA data, respectively. In total, DDA and DIA analysis resulted in 158 and 241 DNA break-dependent phosphosites, respectively, with 67 sites captured by both methods.

We examined the method-specific site identifications and found that most were explained by missing data or scores below the significance cutoff (Supplemental Figure 4). Based on the results of these analyses, we opted to merge all DNA break-dependent phosphosites from the DDA and DIA datasets, obtaining a total of 332 DNA break-dependent phosphosites (Supplemental table 3). In addition, we detected 4,953 phosphorylation events that were not DNA break-dependent. 
Among the DNA break-dependent sites were several previously confirmed Mec1/Tel1 targets, including H2A S129, Cbf1 S45, Zip1 S75, Rad54 T132, and Hed1 T40 (Callender et al., 2016; Downs et al., 2000; Falk et al., 2010; Niu et al., 2009; Smolka et al., 2007)(Figure 2A-C), confirming the high quality of our dataset. In addition, we uncovered many DNA breakdependent phosphorylation events that have only been characterized in non-meiotic cells or that are entirely novel. For example, we identified an additional DNA break-dependent phosphorylation event on histone H3 S57 (Figure 2C), which is predicted to weaken nucleosomal DNA association (Bowman \& Poirier, 2015), and may thus play a role in removing nucleosomes during meiotic DNA repair. We also identified DNA break-dependent phosphorylation on several chromatin factors, including all three subunits of the Sir complex (Sir2, Sir3, Sir4), which have roles in meiotic checkpoint regulation and the timing of meiotic prophase (San-Segundo \& Roeder, 1999; Subramanian et al., 2019)(Figure 2C). Among proteins involved in meiotic DNA repair, we identified additional DNA break-dependent phosphorylation sites on the MRX complex (Mre11, Xrs2), regulators of recombination (Rad52, Sgs1) and the meiotic resolvase complex (Mlh1, Exo1)(Figure 2B,C). Intriguingly, we also observed DNA break-dependent phosphorylation of multiple components of the nucleotideexcision repair machinery ( $\operatorname{Rad} 1, \operatorname{Rad} 7, \operatorname{Rad} 14, \operatorname{Rad} 16, \operatorname{Rad} 23, \operatorname{Rad} 26$; Figure 2B). As there is no known role for nucleotide-excision repair during meiotic prophase, these phosphorylation events may be inhibitory.

We also observed a total of 81 phospho-sites that disappeared during DNA break formation, as they were either enriched in spo11-YF compared to SPO11 samples or were specifically detected in spo11-YF samples (Supplemental Table 4). Amongst these sites were Cdk1-dependent phosphorylation events on Dna2 S17 and S237 (Figure 2B), which are known to regulate Dna2 localization to DNA breaks and may promote Mec1/Tel1-dependent phosphorylation of yet unidentified sites on Dna2 (Chen et al., 2011). Thus, the observed DNA break-dependent reduction in abundance of some of these phosphorylations is likely biologically meaningful.

Several known DNA break-dependent sites were absent from our data. Specifically, neither DDA nor DIA data captured Hop1 T318 or H3 T11 (Carballo et al., 2008; Kniewel et al., 2017). Inspection of the sequences surrounding these sites revealed that the H3 T11 phosphorylation site would reside on a 5 amino acid long tryptic peptide, which is too small for reliable proteomic identification. Conversely, a tryptic peptide with Hop1 T318 phosphorylation would be 49 amino acids long; and larger peptides are typically detected at a low frequency (Swaney et al., 2010).

Finally, we validated one newly identified site, namely the phosphorylation of the yeast casein kinase $1 \delta / \varepsilon$ homologue Hrr25 on S438 (Figure 2C) by raising and purifying a phosphospecific antibody (Supplemental Figure 5). Immunoblotting showed that Hrr25 S438 occurred specifically in response to meiotic DNA break formation and was undetectable in meiotic spo11YF cultures (Figure 2D). Therefore, our data presents a high-quality, rich resource for phosphosignaling during the meiotic DNA break response. 


\section{Phosphorylation sites are enriched for known kinase motifs}

208

209

210

211

212

213

214

215

216

217

218

219

220

221

222

223

224

225

226

227

228

229

230

231

232

233

234

235

236

237

238

239

240

241

242

243

244

245

246

247

248

249

250
To better define substrate selection in response to meiotic DNA break formation, we examined features of the DNA break-dependent phospho-sites in our data. Motif enrichment analysis showed strong enrichment (motif-x, $p$-value cutoff 0.05 ) of predicted consensus sites for Mec1/Tel1 ( $\underline{\mathrm{S} / \mathrm{TQ}})$ and Mek1 (RxxI), the main regulators of the meiotic DNA break response. Approximately $19 \%$ of all DNA break-dependent sites occurred in an S/TQ motif, compared to only $\sim 5 \% \mathrm{~S} / \mathrm{TQ}$ occurrence among all phosphorylation sites detected in our study (Figure $3 \mathrm{~A}$ ). Among DNA break-dependent S/TQ sites, L was the most common amino acid at the -1 position and $E$ was the most common amino acid at the +2 position (Figure 3B). As LS/TQE is known as a high-affinity site for human ATM in in vitro studies (O'Neill et al., 2000), these sites are likely also targeted by the yeast orthologs Mec1/Tel1.

Approximately $28 \%$ of all DNA break-dependent sites localized to RxxS/T motifs, compared to only $\sim 17 \%$ of all detected sites (Figure 3A). Amongst these sites, we observed $S$ as the most common amino acid at the -2 position (Figure $3 \mathrm{C}$ ). The RxxS/T motif is preferred by several kinases in yeast (Mok et al., 2010), but all known Mek1-dependent phosphorylation sites contain a threonine instead of a serine (Callender et al., 2016; Kniewel et al., 2017; Niu et al., 2009). Indeed, among the detected phosphorylation sites with an RxxS/T motif, DNA breakdependent sites were significantly enriched for threonine as the phosphorylated amino acid (hypergeometric test, $p$-value $<0.001$; Supplemental Figure $6 \mathrm{~A}$ ), consistent with the reported sequence preference of Mek1 (Suhandynata et al., 2016).

In a couple of instances, we also observed phosphorylation of RxxIQE sequences (Figure 2C), which combine RxxI and IQE motifs and may thus represent a hybrid target motif for Mek1 and Mec1/Tel1. As Mek1 is activated by Mec1/Tel1, phosphorylation of RxxIQE hybrid motifs by both types of kinases could create a coherent feedforward signal, a common feature in gene regulatory networks that creates signal stability (Mangan \& Alon, 2003). Notably, the two proteins with phosphorylated RxxTQE motifs in our data, Rfm1 and Rfx1, are transcription factors of the DNA damage response, with $\mathrm{Rfm} 1$ preventing premature exit from meiotic prophase (McCord et al., 2003; Xie et al., 1999).

Although our data show a clear enrichment of predicted Mec1/Tel1 and Mek1 motifs, more than half $(\sim 53 \%)$ of all DNA break-dependent phosphosites had neither motif, suggesting other kinases might be catalyzing these phosphorylation events. Motif search failed to identify additional significantly enriched motifs among these sites, possibly because of a lack of sequence preference or because of contributions from multiple kinases. Candidate kinases include Rad53 and Dbf4-dependent kinase (DDK), both of which have been shown to mediate phosphorylation events downstream of Mec1/Tel1/Mek1 and/or meiotic DNA break formation (Bashkirov et al., 2003; Chen et al., 2015; He et al., 2020; Lao et al., 2018), with only DDK having a known consensus motif.

In general, DNA break-dependent phosphorylation events localized to intrinsically unstructured parts of target proteins (Supplemental Figure 6B), presumably reflecting 
increased accessibility and the higher preponderance of serines and threonines in these regions. This trend is not unique to DNA break-dependent phosphorylation events (Supplemental Figure 6B) and has also been noted in previous large-scale phosphoproteomics analyses (Holt et al., 2009). Interestingly, almost one third (116 of 332) of DNA break-dependent phosphorylation events occurred within five amino acid of another DNA breakdependent site, which may either reflect multiple phosphorylation events mediated by the same kinase, or priming events, whereby phosphorylation by one kinase stimulates nearby phosphorylation events by another kinase.

The 332 phosphorylation sites mapped to a total of 226 different proteins which were

\section{Protein levels do not change in response to meiotic DNA breaks}

We tested whether the meiotic DNA break response also affects protein levels. To this end, we quantified proteins in the same replicate cultures described above. This analysis strongly enriched for functions related to meiosis and DNA repair (q-value $<0.2$, Figure $3 \mathrm{D}$ ), implying that many of these phosphorylation events likely are functional. For most proteins, we only identified a single DNA break-dependent site, while two proteins had six DNA breakdependent phosphorylation sites (Figure 3E). One of these proteins is the meiotic chromosome organizer Red1, which has been suggested to be phosphorylated in both DNA break-dependent and -independent manner (Bailis \& Roeder, 1998; de los Santos \& Hollingsworth, 1999; Lai et al., 2011; Wan et al., 2004). Consistent with this notion, our data shows ten additional phosphorylation sites for Red1 that are not DNA break-dependent. One of the DNA breakdependent sites on Red1, T484, fits the consensus motif for phosphorylation by Mek1, but phosphorylation of this site was still detectable at low levels in spo11-YF strains indicating that it is not solely dependent on meiotic DNA break formation. yielded robust quantitative data for just under half of the yeast proteome (2,627 proteins). Measurements were highly correlated between replicates and samples (Supplemental Figure 7A-C). Accordingly, $\log _{2}$ fold changes in response to DNA break formation were narrowly centered on zero (Supplemental Figure $\mathbf{8 A}$ ), indicating a surprisingly steady proteome during meiotic DNA break formation.

Only four proteins changed significantly in abundance between SPO11 and spo11-YF cultures (adjusted p-value < 0.1): the levels of Rad51, Leu2, and Dbp2 were elevated in SPO11 cells; Sml 1 levels were decreased (Figure 4A). We validated the relative changes in Rad51, Sml1, and Dbp2 levels by immunoblotting (Figure 4B-D). Rad51 and Sml1 are known targets of the DNA damage response; Rad51 is a recombinase required for DNA break repair that is induced upon DNA damage and also protected from degradation (Basile et al., 1992; Woo et al., 2020), whereas the ribonuclease reductase RNR inhibitor Sml1 is degraded (Andreson et al., 2010; Zhao, 2001). The resulting changes in abundance are in agreement with our data (Figure 4A-C), indicating that these aspects of the DNA damage response remain active in response to meiotic DNA breaks. Differences in Leu2 levels were expected given that SPO11 cells contained four copies of the LEU2 gene whereas the spo11-YF cells only contained two (Supplemental Table 1). The significantly higher Leu2 levels in the SPO11 strain thus served as a good internal control. Dbp2 is an essential RNA-binding protein without known function 
during meiosis or the DNA damage response. When testing its meiosis-specific depletion, we observed only a minor loss in gamete viability (Supplemental Figure 9A). Taken together, the small overall change in protein levels indicates that the meiotic DNA break response does not involve substantial changes in translation or protein degradation. The robust proteomics data also indicated that the observed changes in protein phosphorylation were not driven by underlying changes in protein abundance (Figure 4E; Supplemental Figure 8B).

\section{Activation of the signaling pathway for damage-dependent transcription}

The robustness of protein abundances in response to meiotic DNA break formation was surprising, as it contrasted with the transcriptional changes that are characteristic of the canonical DNA damage response (Elledge \& Davis, 1990; Gasch et al., 2001; Huang et al., 1998; Jaehnig et al., 2013; Tsaponina et al., 2011). We therefore investigated whether the effector kinases Rad53 and Dun1, which trigger the DNA-damage-dependent transcription changes, were indeed active during the response to meiotic DNA breaks. Western analysis of Rad53 in our experimental strains showed phosphorylated, slower migrating forms of Rad53 only in SPO11 cells but not in spo11-YF cells (Figure 5A), indicating that Rad53 is activated by meiotic DNA breaks. In addition, we detected DNA break-specific phosphorylation of Dun1 at position S10 (Chen et al., 2007) (Supplemental Table 3) and reduction of Sml1 protein levels (Figure 4A,C), both of which are hallmarks of Dun1 activation as Sml1 is a Dun1 target (Zhao \& Rothstein, 2002). Thus, key regulators of the transcriptional response to canonical DNA damage are activated also in response to meiotic DNA break formation.

\section{A transcriptional response to meiotic DNA breaks}

We tested if activated Rad53 and Dun1 induce transcription of DNA damage-response genes during meiosis. To this end, we conducted mRNA-seq experiments using the same strains as described above, comparing mRNA levels of SPO11 and spo11-YF cultures. We found that $7 \%$ of genes ( 373 of 5,386 ) were differentially expressed (adjusted $p$-value $<0.01$ ), and 42 genes $(<1 \%)$ were upregulated more than two-fold in response to DNA break formation. This group contained many genes of the canonical gene expression response to DNA damage, including RNR2, RNR3, and RNR4 (Elledge \& Davis, 1987, 1990; Huang \& Elledge, 1997) (Figure 5B).

We conducted several tests to confirm that, indeed, the proteome is highly fixed despite DNA break-dependent transcriptome changes. We verified that the discordance could not be explained by low coverage of the proteome data. Of the 287 transcriptionally upregulated genes, $165(57 \%)$ were quantified in the proteome data, including $23(54 \%)$ of the 42 genes with $>2$-fold change suggesting that the proteomics experiment captured a representative fraction of the proteome. None of these genes changed at the proteome level. Furthermore, immunoblotting of several DNA break-induced factors, i.e. Rnr4, Frd1, and Pgk1, throughout meiotic prophase confirmed that the protein levels were unaffected by meiotic DNA break formation and stable throughout meiosis both in spo11-YF and SPO11 cells (Figure 5C) despite the increased levels of RNR4, FRD1 and PGK1 transcripts detected by mRNA-seq (Figure 5B). 


\section{Meiotic entry is associated with strong reduction in mRNA abundance}

To further investigate these unexpected results, we analyzed the transcript levels of several genes in a meiotic time course by Northern blotting. We observed two competing effects on mRNA levels. First, all analyzed transcripts experienced a noticeable drop in abundance as cells progressed through meiotic prophase (Figure 5D, E). For vegetatively expressed transcripts, like RNR4, FRD1 and PGK1, overall mRNA abundance during meiosis dropped upon meiotic entry and remained at lower levels throughout the remainder of the time course (Figure 5D,E). This downregulation of RNR4, FRD1, and PGK1 transcripts has also been

\section{Discussion}

In this study, we combined three systems-level approaches, i.e. transcriptomics, observed in wild-type cells undergoing meiosis (Supplemental Figure 9D)(Cheng et al., 2018). Once cells progressed further into meiotic prophase, transcripts that were initially induced upon meiotic entry, such as RAD51 and HOP1 (Figure 5D,E, Supplemental Figure 9B,C), also dropped in abundance. The drops were observed regardless of whether samples were normalized by total cell number or total RNA (Figure 5D,E, Supplemental Figure 9B,C) and suggest that despite stable protein levels, transcripts levels drop when the cells enter meiotic prophase.

Second, as suggested by mRNA-seq results, the analyzed transcripts levels were higher in SPO11 cells compared spo11-YF cells, confirming the induction of a transcriptional program in response to meiotic DNA breaks. However, the overall decrease in transcript abundance during meiosis overshadowed this elevation (Figure 5D,E, Supplemental Figure 9B,C). Taken together, mRNA and protein data suggest that protein levels for these genes are determined at or soon after meiotic entry when mRNA levels are highest, and later upregulation of these genes is not substantial enough to cause protein level changes. proteomics and phosphoproteomics, to capture the breadth of the meiotic DNA break response in S. cerevisiae. Our analyses identified 332 DNA break-dependent phosphorylation events, substantially expanding our current knowledge of the meiotic DNA break response. The breadth of detection also highlights the power of using complementary data acquisition techniques (DDA, DIA) and different analyses of the mass spectra (fold enrichment, presence/absence) for obtaining a large and high-quality dataset. Notably, the two approaches, fold enrichment and presence/absence, yielded qualitatively distinct groups of phosphorylation events. Fold enrichment analysis recovered many phosphorylation events that are not specific to meiosis, such as Hta1/2 S129 ( $\mathrm{Y}-\mathrm{H} 2 \mathrm{~A})$ and $\mathrm{Cbf1} \mathrm{S} 45$, but are induced by different forms of canonical DNA-damage signaling (Cobb et al., 2005; Smolka et al., 2007). In comparison, presence/absence analysis recovered most of the known meiosis-specific phosphorylation events, including Zip1 S75, Hed1 T40 and Rad54 T132, which therefore appear to be regulated in an on/off-switch like manner in response to meiotic DNA breakage. Thus, the meiotic DNA break response elaborates on features of the canonical DNA damage response by adding a large number of targets that specifically respond to meiotic DNA breaks. 
Our data set complements and expands on a published phosphoproteomics analysis that compared strains with active or inactive Mek1 kinase (Suhandynata et al., 2016) by identifying targets of all DNA break-dependent kinases and thus providing a comprehensive view of the phosphorylation events in response to DNA breaks. Importantly, our experimental setup also blocked cells from exiting prophase. As inactivation of Mek1 or Spo11 allows cells to prematurely exit from meiotic prophase (Suhandynata et al., 2016), phosphorylation differences between prophase and metaphase/anaphase can identify a substantial number of cell-cycledependent hits that are difficult to distinguish from the immediate meiotic DNA break response. Our analyses therefore provide a snapshot of the immediate DNA break response prior to exit from meiotic prophase.

Surprisingly, DNA break formation did not greatly impact the proteome of meiotic prophase. Our results suggest that this proteomic robustness arises from a combination of high protein stability and diminishing mRNA abundances, likely due to increased mRNA degradation. We show that many vegetatively expressed genes maintain their pre-meiotic protein levels throughout meiotic prophase, while their mRNA levels plummet after cells enter meiosis. Thus, although meiotic DNA breaks induce a clear transcriptional response, the increases in transcript levels were not large enough to alter the protein levels in a detectable manner.

The stability of protein abundances during meiotic prophase is consistent with the finding that most proteins are long-lived and that concentrations drop primarily as a consequence of dilution due to cell division (Martin-Perez \& Villén, 2017), which does not occur during meiotic prophase. Targeted proteolysis via the meiosis-specific APC/Ama1 ubiquitin ligase or other mechanisms are important for meiotic prophase progression in yeast and mice (Kwon et al., 2003; Okaz et al., 2012), but the unchanged proteome observed here suggests that these mechanisms, while clearly active, do not become differently active in response meiotic DNA break formation. Rather, DNA break-dependent protein abundance changes were limited to a few select proteins with specialized modes of regulation, including Sml1, whose proteolysis is triggered by phosphorylation and subsequent ubiquitination (Zhao \& Rothstein, 2002) and Rad51, which is protected from degradation by phosphorylation (Woo et al., 2020).

The drop in transcript levels as cells enter the meiotic program may be related to the unique aspects of mRNA metabolism in meiotic prophase. For example, N6-adenosine methylation of transcripts regulates both meiotic entry and meiotic commitment (Agarwala et al., 2012; Bushkin et al., 2019; Shah \& Clancy, 1992). In addition, RNA stability is uncoupled from polyA-tail length during meiosis, likely through differential regulation of the RNA degradation protein Xrn1 (Wiener et al., 2021). Intriguingly, we observed DNA break dependent phosphorylation of Xrn1 on S1510. Although the effect of this phosphorylation on Xrn1 activity is unknown, it is possible that this phosphorylation event might reduce Xrn1 activity. A subsequent general slowdown in mRNA degradation during meiotic DNA breakage could explain why we observed not only the predicted induction of canonical DNA-damage response genes but also increased mRNA abundances of house-keeping genes, such as PGK1. Such potential interplay 
of the meiotic DNA break response with the mRNA degradation machinery warrants further analysis.

Taken together, our results suggest extensive rewiring of the canonical DNA-damage response in the context of meiotic DNA breaks by deemphasizing the role of proteome changes and instead exploiting and expanding post-translational signaling. We speculate that this shift toward posttranslational signaling reflects the unique needs created by the programmed induction of nearly 200 DNA breaks. As protein modifications have the crucial potential to create spatially distinct and constrained signals, they are uniquely suitable to support the patterning of the meiotic recombination landscape and the creation of local or chromosome-wide dependencies in a shared nuclear environment, which is a key feature of meiotic recombination (Kar \& Hochwagen, 2021).

\section{Methods}

\section{Yeast strains and meiotic time courses}

All strains used in this study were derived from the SK1 background. Supplemental Table 1 lists the genotypes of these strains. Meiotic time courses were set up by growing cells at room temperature $\left(25^{\circ} \mathrm{C}\right)$ in rich medium (YPD) for $\sim 24$ hours, followed by inoculation at a final $\mathrm{OD}_{600}$ of 0.3 in premeiotic BYTA medium (1\% yeast extract, $2 \%$ bactotryptone, $1 \%$ potassium acetate, $50 \mathrm{mM}$ potassium phtalate) and growth for $16-17$ hours at $30^{\circ} \mathrm{C}$. Cells were washed twice in sterile water and diluted to $1.9 \mathrm{OD}_{600}$ in SPO medium $(0.3 \%$ potassium acetate) and sporulated at $30^{\circ} \mathrm{C}$. The time of resuspension in SPO was defined as the $0 \mathrm{~h}$ time point.

442 We collected $150 \mu \mathrm{l}$ of meiotic culture at the indicated time points and fixed cells with $350 \mu \mathrm{l}$ $100 \%$ ethanol. The samples were stored at $4^{\circ} \mathrm{C}$ until further analysis. To prepare cells for flow cytometry, cell pellets were resuspended in $500 \mu \mathrm{l} 50 \mathrm{mM} \mathrm{Na-Citrate}$ and treated with $0.7 \mu \mathrm{l}$ RNAse A (20-40 mg/ml stock; Sigma) at $50^{\circ} \mathrm{C}$ for at least 1 day. $5 \mu$ Proteinase K (VWR, 20 $\mathrm{mg} / \mathrm{ml}$ ) was added to the samples and incubated at $50^{\circ} \mathrm{C}$ for at least 1 day before addition of $500 \mu \mathrm{l}$ of $50 \mathrm{mM}$ Na-Citrate with $0.1 \mu \mathrm{l}$ SYTOX green (Invitrogen, $5 \mathrm{mM}$ solution in DMSO). Prior to cytometry, samples were sonicated for approximately 5 seconds at $10 \%$ amplitude. Signal was collected using a BD Accuri C6 Flow cytometer.

\section{Preparation of protein samples for mass spectrometry}

451 We collected $50 \mathrm{ml}$ meiotic culture at 5 hours into meiosis, harvested cells at $4000 \mathrm{rpm}$ for 3 minutes, and washed once with ice-cold sterile water at $4^{\circ} \mathrm{C}$. Cell pellets were stored at $-20^{\circ} \mathrm{C}$ until further processing. We used MS grade water in all the following steps and solutions. Proteins were extracted using an $8 \mathrm{M}$ urea lysis buffer $(8 \mathrm{M}$ urea, $50 \mathrm{mM}$ Tris- $\mathrm{HCl}, 75 \mathrm{mM} \mathrm{NaCl}$, 1x Calbiochem protease inhibitor, $1 \mathrm{mM}$ PMSF, 1x Thermo Fisher halt phosphatase and protease inhibitor). $2 x$ cell pellet volume of lysis buffer and $1 x$ cell pellet volume of acid washed glass beads (Millipore Sigma) were added to $1.5 \mathrm{ml}$ tubes, and samples were agitated with 
Digital Vortex Mixer (Fisher Scientific) at $4^{\circ} \mathrm{C} 3$ times for 10 minutes separated by 2-minute cooling intervals. The samples were centrifuged at 13,000 rpm for 20 minutes and the supernatants were transferred to new $1.5 \mathrm{ml}$ tubes. Protein concentrations were measured using a Quick Start Bradford Protein Assay (Bio-Rad) and $200 \mu \mathrm{g}$ of protein was processed for preparation of WCE protein samples.

Proteins were reduced in $5 \mathrm{mM}$ dithiothreitol (DTT) at $37^{\circ} \mathrm{C}$ for 30 minutes and alkylated in $15 \mathrm{mM}$ iodoacetamide at room temperature $\left(25^{\circ} \mathrm{C}\right)$ for 30 minutes in the dark. The alkylation was stopped by increasing the DTT concentration to $10 \mathrm{mM}$ and incubating at room temperature for 15 minutes. Urea concentration was lowered by increasing the sample volume to $200 \mu \mathrm{l}$ (7fold dilution) with $50 \mathrm{mM}$ Tris- $\mathrm{HCl} \mathrm{pH} 8$ solution. We added $3 \mu \mathrm{g}$ Trypsin Gold (Promega) to each sample for digestion and incubated samples at $37^{\circ} \mathrm{C}$ overnight (approximately 16 hours) while shaking. Digestion was stopped by adding formic acid to a final concentration of $1 \%$. Samples were dried under vacuum until all liquid was removed and resuspended in Buffer $\mathrm{C}$ (95\% water, $5 \%$ acetonitrile, $0.1 \%$ formic acid). HyperSep tips (ThermoFisher Scientific) were used for clean-up following the kits instructions. Elution peptides were dried under vacuum until completely dry, resuspended in $100 \mu$ amount of Buffer $\mathrm{C}$ and stored at $-80^{\circ} \mathrm{C}$. Peptide concentrations were determined using Pierce Quantitative Fluorometric Peptide Assay

475 (ThermoFisher Scientific).

\section{Preparation of phospho-peptide enriched samples}

We reduced $2,000 \mu \mathrm{g}$ of protein samples and alkylated as described above. For phosphopeptide samples the volume was increased to 2,000 $\mu$ l (7-fold dilution) and $30 \mu \mathrm{g}$ Trypsin Gold (Promega) was added to each sample. After the samples were cleaned-up, phosphorylated peptides were enriched using the High-Select $\mathrm{TiO}_{2}$ Phosphopeptide Enrichment Kit (ThermoFisher Scientific) according to the manufacturer's instructions.

\section{Mass spectrometry analysis for DDA data}

Samples were analyzed using an EASY-nLC 1000 (ThermoFisher Scientific) coupled to a QEHF instrument (ThermoFisher Scientific). Peptides were separated using a PepMap C18 column (Thermo Fisher Scientific) with 155 minute gradient of Buffer A (0.1\% Formic Acid) and Buffer B ( $80 \%$ Acetonitrile, $0.1 \%$ Formic Acid). Full MS spectra were collected in a scan range of 375 1500 with resolution of 120,000 . AGC target was set to $3 \mathrm{e} 6$ and top 20 peptides were selected for further analysis with an isolation window of $1.5 \mathrm{~m} / \mathrm{z}$ with a maximum injection time of 100 $\mathrm{m} / \mathrm{s}$. MS2 spectra were collected with a resolution of 30,000 and AGC target $2 \mathrm{e} 5$ with an isolation window of $1.5 \mathrm{~m} / \mathrm{z}$ and normalized collision energy (NCE) of 27 in centroid mode.

\section{Mass spectrometry analysis for DIA data}

492 For DIA runs, a full MS scan was collected with a resolution of 120,000 and AGC target of $3 e 6$ 60,000 and AGC target of 1e6. Maximum injection time was set to auto, and normalized 


\section{Data analysis of DDA data}

Raw data were processed in MaxQuant (version 1.5.5.1)(Tyanova et al., 2016) using the proteome of Saccharomyces cerevisiae strain S288C (downloaded from Uniprot on August 8 2017) with default settings. For phospho-enriched samples Phospho(STY) was selected as a variable modification. Data was further analyzed and graphed in custom made $\mathrm{R}$ scripts using packages tidyverse, ggplot2 and limma (Ritchie et al., 2015; Wickham, 2016; Wickham et al., 2019). Proteins from contamination and reverse search were filtered out. For protein level data, LFQ intensities were first normalized to parts per million and $\log _{2}$ transformed. $\log _{2}$ transformed values were tested for significance analysis using limma. For analysis of phospho-proteome changes, we used the Phospho(STY) file. Phosphorylation level data was filtered out to only include phosphosites with 0.9 localization probability. Then the phosphorylation site intensities were normalized to parts per million and $\log _{2}$ transformed before significance analysis with limma.

DIA data was analyzed using Spectronaut ( $v$ 13.8.190930.43655) against a project-specific spectral library (phospho-DDA data). Perseus plug-in Peptide Collapse program was used to convert the Spectronaut (Biognosys) report file to intensity values at the peptide level (BekkerJensen et al., 2020). Peptide level intensity values were normalized to parts per million and $\log _{2}$ transformed before performing significance analysis using limma.

\section{GSEA and motif analysis}

Gene set enrichment analysis was performed using $\mathrm{R}$ package clusterProfiler using the enrichGO function (Yu et al., 2012). Motif analysis was performed with sequences of 3 amino acids on $\mathrm{N}$ and $\mathrm{C}$ terminal sides around the phospho-sites using rmotif- $\mathrm{x}$ with $\mathrm{p}$-value cut-off of 0.05 (Wagih et al., 2016). Sequences of all phosphosites detected in our study were used as the

522 background dataset.

\section{3}

\section{Preparation of mRNA-Seq samples}

\section{RNA Extraction}

We harvested $1.6 \mathrm{ml}$ of meiotic culture at 4 hours into meiosis and centrifuged samples at 3000 rpm for 5 minutes at $4^{\circ} \mathrm{C}$. All supernatant was removed and the pellet was resuspended with 1 $\mathrm{mL}$ of Tris-EDTA (10 mM Tris pH 8, $1 \mathrm{mM}$ EDTA) buffer. The samples were spun down again and the supernatant was removed. The samples were stored at $-80^{\circ} \mathrm{C}$ until further processing. RNA extraction was performed using the Rneasy Mini Kit (Qiagen). $600 \mu \mathrm{l}$ of RLT buffer with 1\%

$530(\mathrm{v} / \mathrm{v}) \beta$-mercaptoethanol and $\sim 200 \mathrm{mg}$ glass beads were added to the pellets. The samples were 531 agitated for 20 minutes at $4^{\circ} \mathrm{C}$ and spun down at $14,000 \mathrm{rpm}$ for 2 minutes. Supernatant was 
532 transferred to a new microcentrifuge tube and mixed 1:1 with $70 \%$ ethanol. Samples were

533 transferred to Rneasy columns and RNA extraction was completed following the kit's instructions. We measured the RNA integrity using Agilent RNA screentape and RNA concentration using Qubit RNA HS assay kit (ThermoFisher Scientific). We used $1.2 \mu \mathrm{g}$ total RNA for mRNA purification. mRNAs were purified using Sera-Mag oligo(dt) magnetic particles (Sigma-Aldrich). mRNAs were fragmented with Ambion mRNA fragmentation buffer and fragmented mRNAs were purified using RNeasy MinElute Kit (Qiagen). Final elution volume was $9 \mu$ l.

First-strand synthesis was performed in a similar manner as described in (Parkhomchuk et al., 2009). For first-strand synthesis, $8 \mu \mathrm{l}$ fragmented mRNAs were mixed with $1 \mu \mathrm{l}$ of random hexamers (Invitrogen) and $1 \mu \mathrm{l}$ of $10 \mathrm{mM}$ dNTPs. The samples were incubated at $65^{\circ} \mathrm{C}$ for $5 \mathrm{~min}$ and chilled on ice for 1 minute. We added $10 \mu$ l of a master mix with final concentrations of $1 \mathrm{X}$ RT Buffer (ThermoFisher Scientific), $10 \mathrm{mM} \mathrm{MgCl}, 20 \mathrm{mM} \mathrm{DTT}, 4 \mathrm{U} / \mu \mathrm{l}$ RnaseOUT (ThermoFisher Scientific) and $20 \mathrm{U} / \mu \mathrm{l}$ of SuperScript III RT (ThermoFisher Scientific) to the RNA samples. The samples were then first incubated at $25^{\circ} \mathrm{C}$ for 10 minutes, followed by a 50 -minute incubation at $50^{\circ} \mathrm{C}$. The reaction was stopped by incubating samples at $75^{\circ} \mathrm{C}$ for 15 minutes. For dNTP cleanup, $80 \mu \mathrm{l}$ water, $1 \mu \mathrm{l}$ glycogen, $10 \mu \mathrm{l} 3 \mathrm{M} \mathrm{NaOAc}$ (pH 5.2), and $200 \mu \mathrm{l}$ cold ethanol were added to the samples. Samples were stored at $-80^{\circ} \mathrm{C}$ for $3-7$ days. Samples were centrifuged at $14,000 \mathrm{rpm}$ for 20 minutes at $4^{\circ} \mathrm{C}$. Supernatant was removed and $500 \mu \mathrm{l}$ of cold $75 \%$ ethanol was added to the samples. Samples were centrifuged again at $14,000 \mathrm{rpm}$ for 10 minutes at $4^{\circ} \mathrm{C}$. Supernatant was removed and samples were resuspended in a mixture composed of $51 \mu \mathrm{l}$ RNAse-free water, $1 \mu \mathrm{l}$ of 10X RT buffer, $1 \mu \mathrm{l} 100 \mathrm{mM}$ DTT, $2 \mu \mathrm{l}$ of $25 \mathrm{mM}$ $\mathrm{MgCl}_{2}$. Second-strand synthesis was performed as described in (Parkhomchuk et al., 2009). at 1:20 and $1 U$ of UNG enzyme (Thermo Fisher Scientific) was added before PCR amplification to digest uridine containing templates to produce directional libraries. For uridine digestion, the samples were incubated at $37^{\circ} \mathrm{C}$ for 15 minutes and the reaction was terminated by incubation at $98^{\circ} \mathrm{C}$ for 10 minutes. Amplified DNA was run on a $1.5 \%$ agarose gel and DNA between 250 bp and 600 bp was extracted using a Qiagen Gel Extraction kit with a MiniElute column. DNA concentrations were measured using Qubit dsDNA HS Assay Kit (ThermoFisher Scientific) and KAPA library quantification kit (Roche). DNA sizes were checked with Agilent High Sensitivity D1000 ScreenTape. 75-bp pair-ended sequencing was performed on a NextSeq 500 instrument.

\section{Analysis of RNA-Seq samples}

568 RNA-Seq reads were mapped to the SK1 genome using the nf-core RNA-Seq pipeline (Ewels et 569 al., 2020; Patel et al., 2021; Yue et al., 2017). We used the salmon.merged.gene_counts.rds file 570 from salmon output for further analysis. Combat-Seq was used for batch correction and DeSeq2 
571 was used for principal components analysis and for differential gene expression analysis (Love 572 et al., 2014; Zhang et al., 2020).

\section{Immunoblotting}

574 For immunoblotting, $5 \mathrm{ml}$ samples were collected at the indicated time points. The samples 575 were spun down at 2,500 rpm for 2.5 minutes, and pellets were resuspended in $5 \%$ TCA. The samples were kept on ice for at least 10 minutes after resuspension. The samples were washed with $500 \mu \mathrm{l} 1 \mathrm{M}$ Tris, and resuspended in $80 \mu \mathrm{l}$ of TE+DTT (0.8XTE, $200 \mathrm{mM}$ DTT) buffer. After the addition of $30 \mu \mathrm{l} 5 \mathrm{x}$ SDS buffer $(190 \mathrm{mM}$ Tris-acetate, $6 \% \beta$-mercaptoethanol, 30\% glycerol, $20 \%$ SDS, $0.05 \%$ bromophenol blue ), the samples were incubated at $100^{\circ} \mathrm{C}$ for 5 minutes and stored at $-80^{\circ} \mathrm{C}$ immediately. Proteins were run in handcast 10\% 29:1 (acrylamide: bisacrylamide) gels for Hrr25 blots and handcast 8\% 29:1 (acrylimide: bis-acrylimide) gels for Rad53 blots. 4\%-20\% gradient gels (Bio-Rad) were used for Sml1 blots and 4\%-15\% gradient gels (Bio-Rad) were used for Frd1-13myc, Rnr4-13myc, and Rad51 blots. All blots were blocked with $5 \%$ milk. Primary antibodies were used at the following concentrations; Hrr25 ph-S438 (rabbit, 1:1000), Rad53 (goat, yc-19 Santa Cruz) at 1:500, Sml1(rabbit, AgriSera) at 1:1000, $\beta$ actin (rabbit, CST) at 1:1000, Myc-tag at 1:1000 (rabbit, CST). Anti-rabbit secondary antibody (Kindle Biosciences) was used at 1:2000, anti-goat secondary antibody (Kindle Biosciences) was used at 1:1000. The blots were visualized using KwikQuant Imager (Kindle Biosciences). The phospho-specific Hrr25 ph-S438 antibody was raised by Covance against the synthetic target peptide Ac-QQRD(pS)QEQQC-amide.

For Northern blotting, $6 \mathrm{ml}$ samples were collected at the indicated time points, spun down at $2,500 \mathrm{rpm}$ for 2.5 minutes and stored in $2 \mathrm{ml}$ microcentrifuge tubes at $-80^{\circ} \mathrm{C}$ immediately. Pellets were overlaid with $350 \mu \mathrm{l}$ acid phenol chloroform pH4.5 (Thermo Fisher Scientific). After addition of $100 \mathrm{mg}$ glass beads and $350 \mu \mathrm{l}$ RNA buffer $1(300 \mathrm{mM} \mathrm{NaCl}, 10 \mathrm{mM}$ TrisHCl pH 6.8, $1 \mathrm{mM}$ EDTA, $0.2 \%$ SDS) samples were agitated at $4^{\circ} \mathrm{C}$ for 10 minutes in a Disruptor Genie (Scientific Instruments). Phases were separated by centrifuging 10 minutes at $14,000 \mathrm{rpm}$ at $4^{\circ} \mathrm{C}$ and 300 $\mu \mathrm{l}$ of the aqueous phase were precipitated in $1 \mathrm{ml}$ cold $100 \%$ ethanol at $4^{\circ} \mathrm{C}$ for 10 minutes. RNA was collected by centrifuging for 5 minutes at $14,000 \mathrm{rpm}$ at $4^{\circ} \mathrm{C}$ and pellets were resuspended in RNA buffer 2 (10 $\mathrm{mM}$ TrisHCI pH 6.8, $1 \mathrm{mM}$ EDTA, $0.2 \%$ SDS) at $65^{\circ} \mathrm{C}$ for 20 minutes before storing at at $-20^{\circ} \mathrm{C}$. RNA concentration was determined using a NanoDrop instrument. Samples were denatured for 10 minutes at $65^{\circ} \mathrm{C}$ in denaturation mix (40 mM MOPS $\mathrm{pH} 7.0,50 \%$ formamide, $6.5 \%$ formaldehyde) and separated in a $1.1 \%$ agarose gel containing $6.2 \%$ formaldehyde and $40 \mathrm{mM}$ MOPS $\mathrm{pH}$ 7.0. RNA was blotted onto a HybondN+ membrane using neutral transfer in 10x SSC and UV crosslinked. Radioactive probes were synthesized from gel-purified templates using a Prime-it RmT Random Labeling Kit (Agilent) and alpha- ${ }^{32} \mathrm{P}$ dCTP (Perkin Elmer). Templates were produced by PCR using the following primers (RNR4: $\mathrm{F}$ 5'- cag ccg tag att cgt gat gtt ccc -3', R 5'- gcg gac tta gac atg tca ctg gcc -3'; FRD1: F 5'- ggt ttg 
610 gcc ggg ctg gct gc -3', R 5'- gca taa ttg ggc gac agt gat tgg -3'; RAD51: F 5'- cag ctt cag tac ggg 611 aac ggt tcg -3', R 5'- gcc ata cca cca tca act tgg gcg -3'; HOP1: F 5'- ccc aat ccc tgg aac ctt tac

612 ccc -3', R 5'- gct cct gta ggg ttg acg acg gag -3'; PGK1: F 5'- tga ctt caa cgt ccc att gga cgg -3', 613 R 5'- aac acc tgg acc gt cca gac -3'). Signals were measured using a Typhoon FLA9000 614 instrument.

\section{Data Availability}

618 All mass spectrometry data are deposited at the PRIDE databases PXD031779 and

619 PXD031781. RNA-seq data are deposited at the GEO database GSE197022.

\section{Acknowledgements}

$622 \mathrm{AH}$ acknowledges funding by the US National Institutes of Health (R01GM11171 and

623 R01GM123035). CV acknowledges funding by the US National Institutes of Health

624 (R35GM127089 and 75N93019C00052/NH/NIH HHS/United States). We thank the NYU

625 Department of Biology Sequencing Core for technical assistance and data processing. 


\section{Figures}

\section{Main Figures}

A

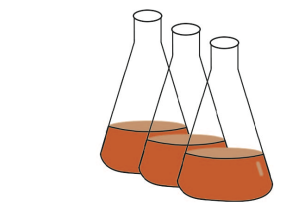

spo11-YF (no breaks)

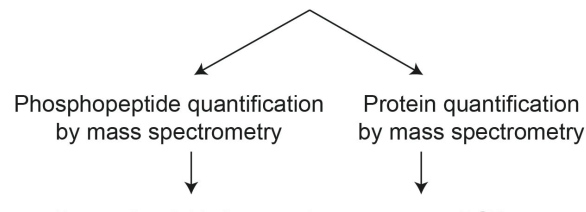

Determine fold changes in response to DSBs

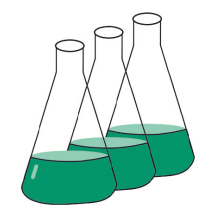

SPO11 (breaks) mass spectrometry
B Detection patterns of phosphosites

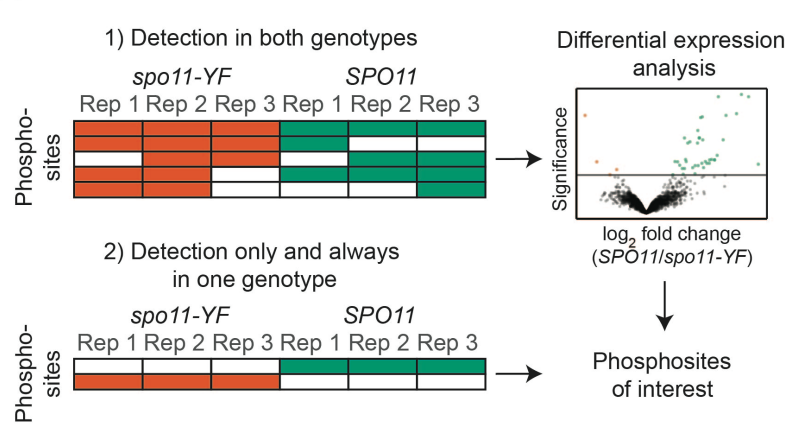

Kar et al., Figure 1

Figure 1: Workflow and experimental setup.

(A) We extracted proteins from synchronous meiotic cultures and quantified the phosphopeptides and proteins obtained from SPO11 and spo11-YF cells. Proteomics and phosphoproteomics experiments both had 3 biological replicates.

(B) Quantitative and qualitative strategies were used to classify phosphorylation sites of interest. Filled rows represent non-zero intensity values for the phosphosites. When there were enough non-zero intensity values, differential expression analysis was used to classify DNA break-dependent sites or phosphorylation sites that were lost in response to DNA breaks (quantitative approach). In addition, we used a qualitative approach by analyzing detection patterns for phosphosites. When a phosphosite was present in all replicates of SPO11 and absent in all Spo11-YF samples, it was designated as a DNA break-dependent site. If a site was present in all replicates of spo11-YF and absent in all SPO11 samples, it was categorized as lost in response to DNA breaks. 

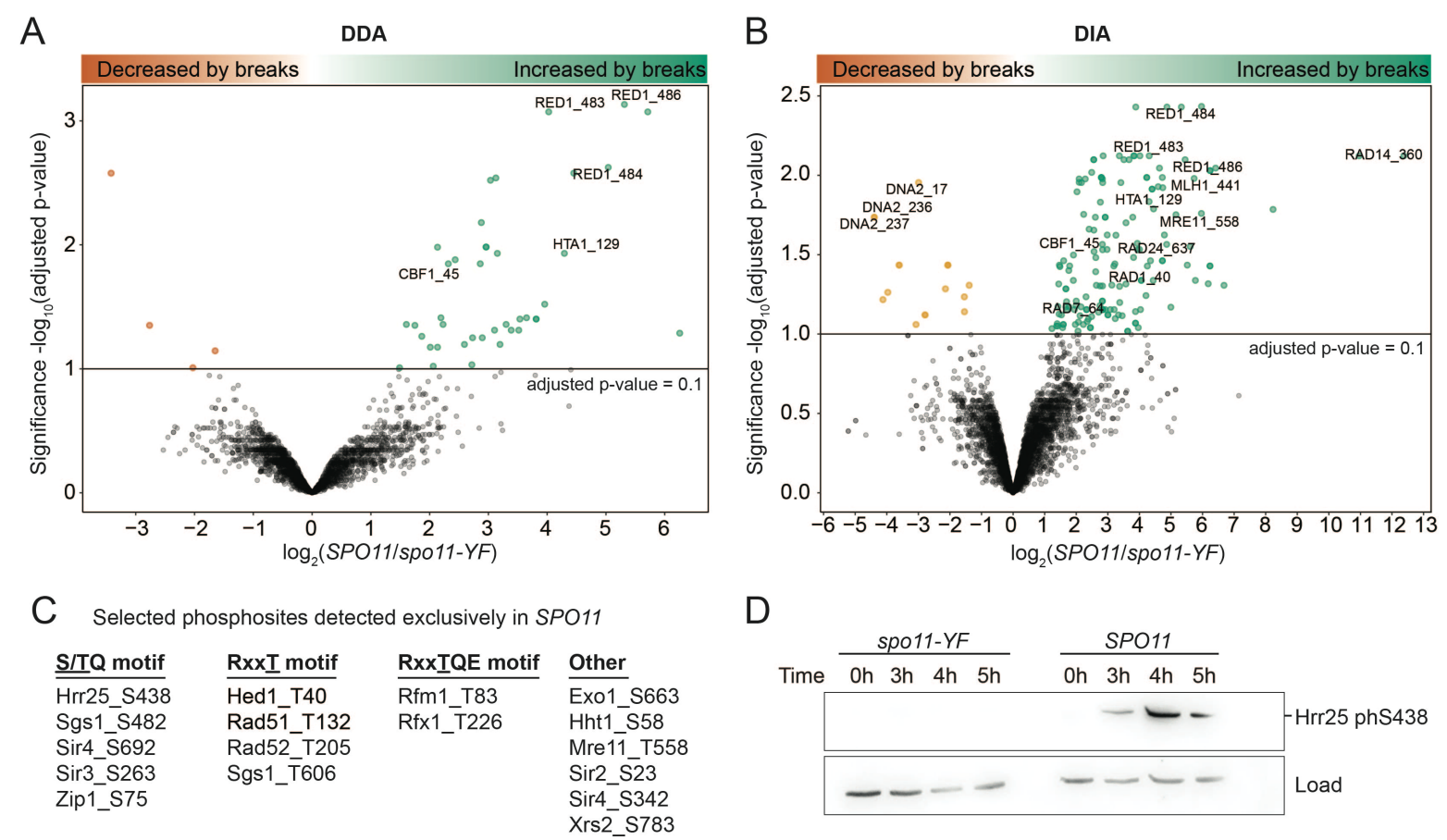

Kar et al., Figure 2

Figure 2: Changes in protein phosphorylation in response to meiotic DNA breaks.

(A) A volcano plot showing results of differential expression analysis for DDA data, each dot representing a phosphosite. $\log _{10}$ (Benjamini \& Hochberg adjusted $p$-value) is shown on the $y$-axis and $\log _{2}$ fold change is shown on the $x$-axis.

(B) A volcano plot showing results of differential expression analysis for DIA Data, each dot representing a phosphopeptide. Labels indicate the phosphorylation sites on peptides.

(C) A table listing selected DNA break-dependent phosphorylation sites discovered by the presence/absence analysis; sites in black have been previously described (see Supplemental Table 3 for the complete list).

(D) A western blot showing DNA break dependence of Hrr25 S438 phosphorylation. $\beta$-actin was used as a loading control. 


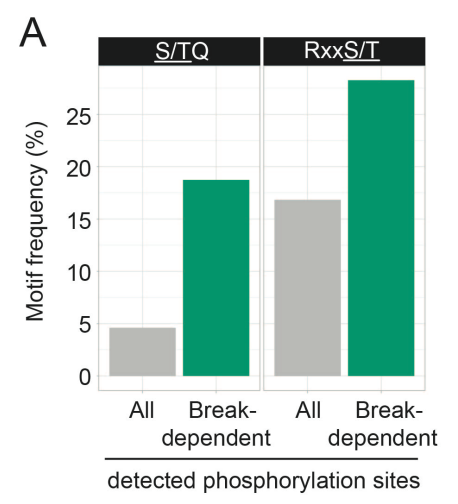

B Break-dependent $\underline{\mathrm{S} / \mathrm{TQ}}$ sites $(\mathrm{n}=59)$

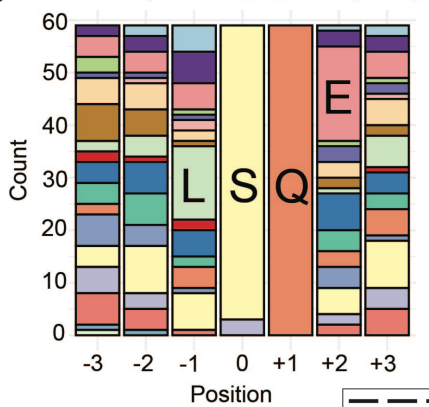

C Break-dependent Rxx $\underline{\mathrm{S} / \mathrm{T}} \operatorname{sites}(\mathrm{n}=89)$ Amino acids

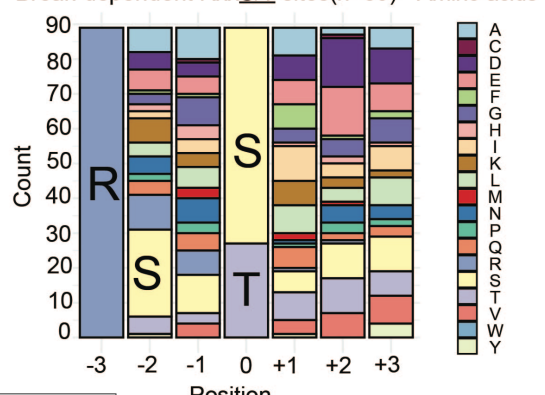

D

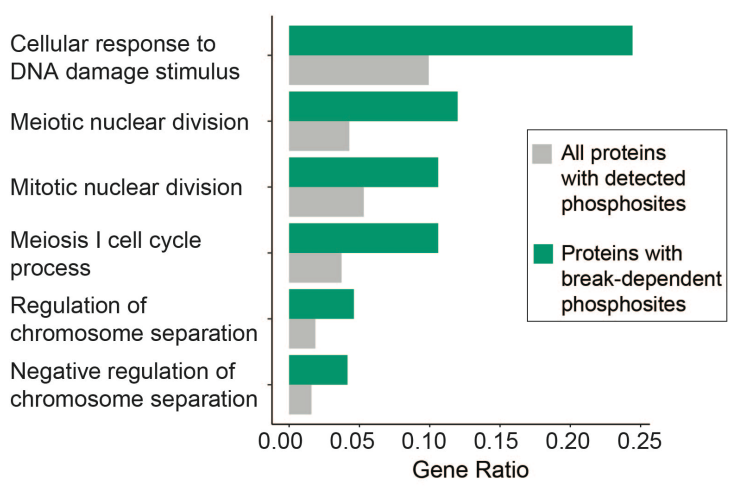

Kar et al., Figure 3

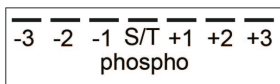

653

654

655

656

657

658

659

660

661

662

663

664

665

666

667
E

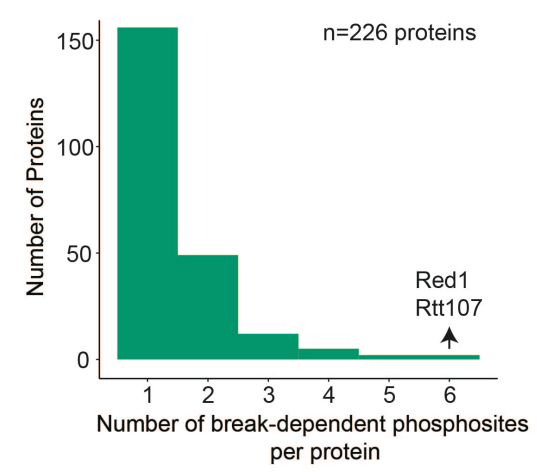

Figure 3: Characteristics of DNA break-dependent phosphorylation events

(A) DNA break-dependent sites were enriched for Mec1/Tel1 ( $\underline{\mathrm{S} / \mathrm{TQ}}$ ) and Mek1(RxxI) consensus motifs, compared to all phosphorylation sites detected in our study.

(B) Stacked bar graph representing the distribution of amino acids surrounding the DNA break-dependent $\underline{S} / \mathrm{TQ}$ sites. The most frequent amino acids at the +1 and -1 position were leucine $(\mathrm{L})$ and glutamic acid $(\mathrm{E})$, respectively.

(C) Stacked bar graph representing the distribution of amino acids surrounding the DNA break-dependent $\mathrm{RxxS/T}$ sites. Serine (S) at the -2 position was the most frequent amino acid, while there was no striking feature for the other positions.

(D) Bar-graphs showing the results of functional enrichment analysis of proteins with DNA break-dependent phosphosites

(E) Bar graph showing the distribution of detected DNA break-dependent phosphorylation sites per protein. 
A

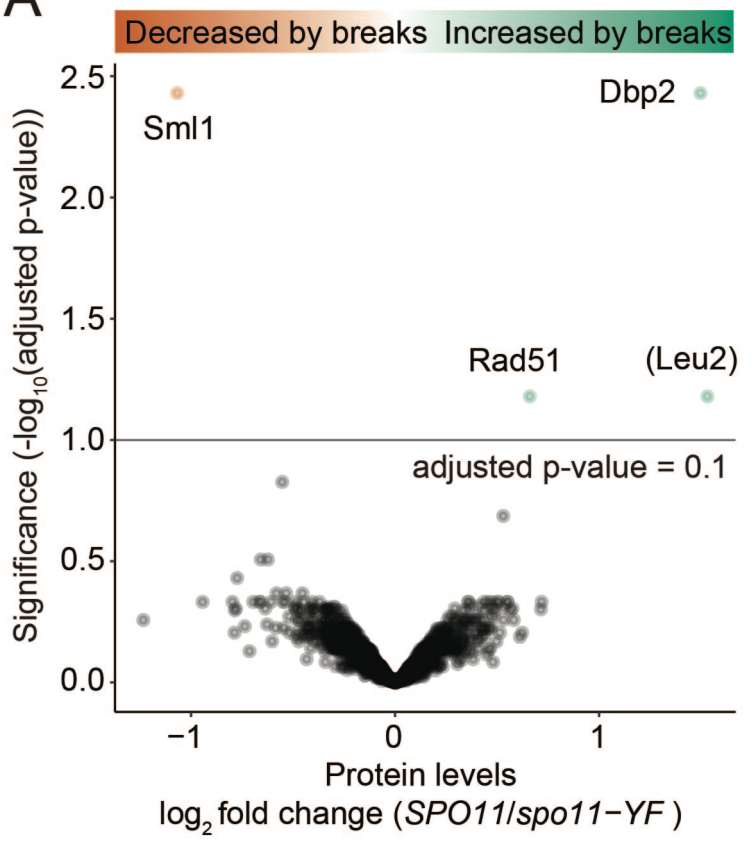

B

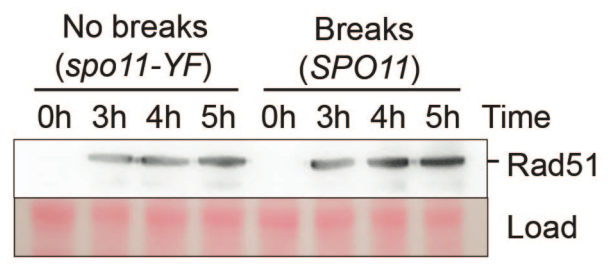

C
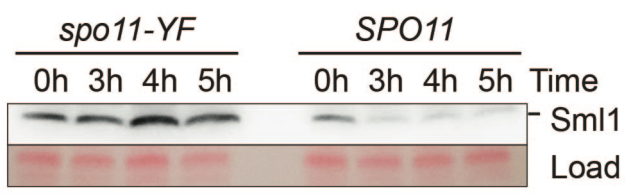

D

spo11-YF SPO11

Oh $5 \mathrm{~h}$ Oh $5 \mathrm{~h}$ Time in meiosis

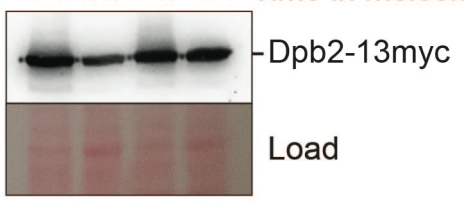

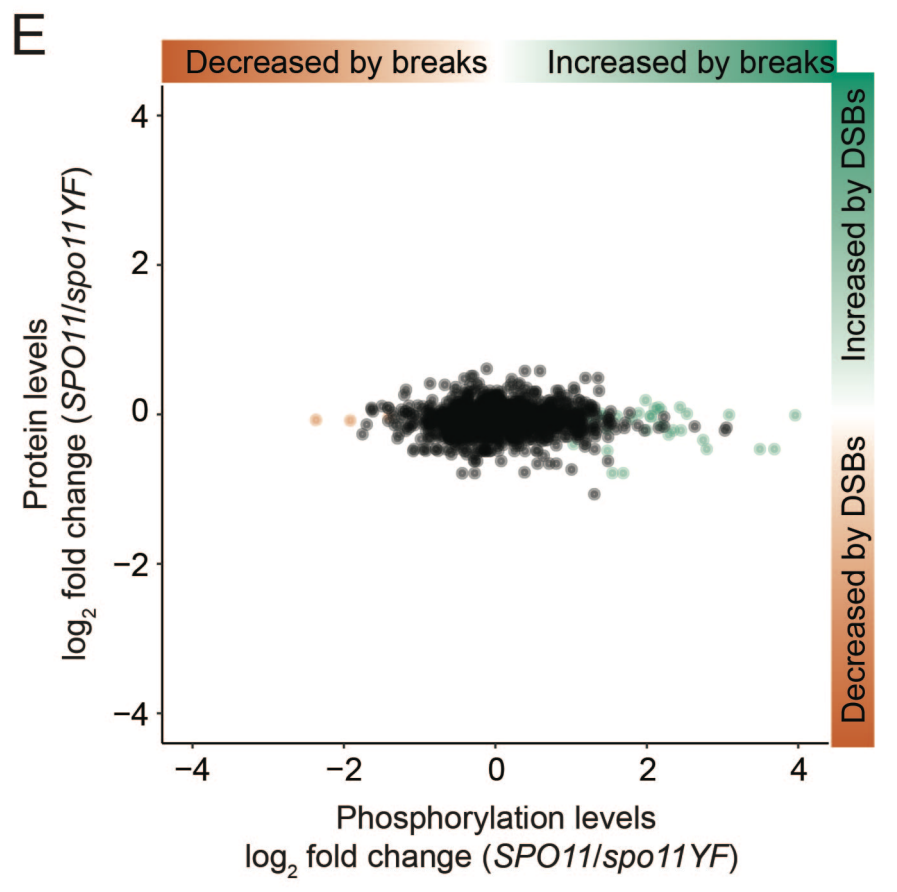

Kar et al., Figure 4 
668 Figure 4: Only a few proteins change in abundance in response to meiotic DNA breaks.

669 (A) A volcano plot showing differentially expressed proteins, each dot represents a protein. The $y$-axis shows $-\log _{10}$ (Benjamini \& Hochberg adjusted $p$-value) and the $x$-axis shows $\log _{2}$ fold change.

(B) Western blot analysis of Rad51 in spo11-YF and SPO11 cells during meiosis is shown. Ponceau $S$ was used as the loading control.

(C) Comparison of Sml1 levels in spo11-YF and SPO11 cells during meiotic prophase. Sml1 was diminished after 3 hours into meiosis concomitantly with DNA break formation, Ponceau $\mathrm{S}$ staining of the membrane was the loading control.

(D) Assessment of Dbp2 levels by western blotting prior to meiosis (Oh) and during meiotic prophase (5h) is shown. Since there are no Dbp2 antibodies available, Dbp2 was tagged with a 13xmyc tag and anti-myc antibody was used for detection of Dbp2. Ponceau S was the the loading control.

(E) Plot showing correlation between protein level $\log _{2}$ fold changes (y-axis ) and phosphosite level $\log _{2}$ fold changes (x-axis). Each dot represents a phosphosite. While $\log _{2}$ fold changes for phosphosites distributed widely, protein $\log _{2}$ fold changes for proteins centered around 0 . 

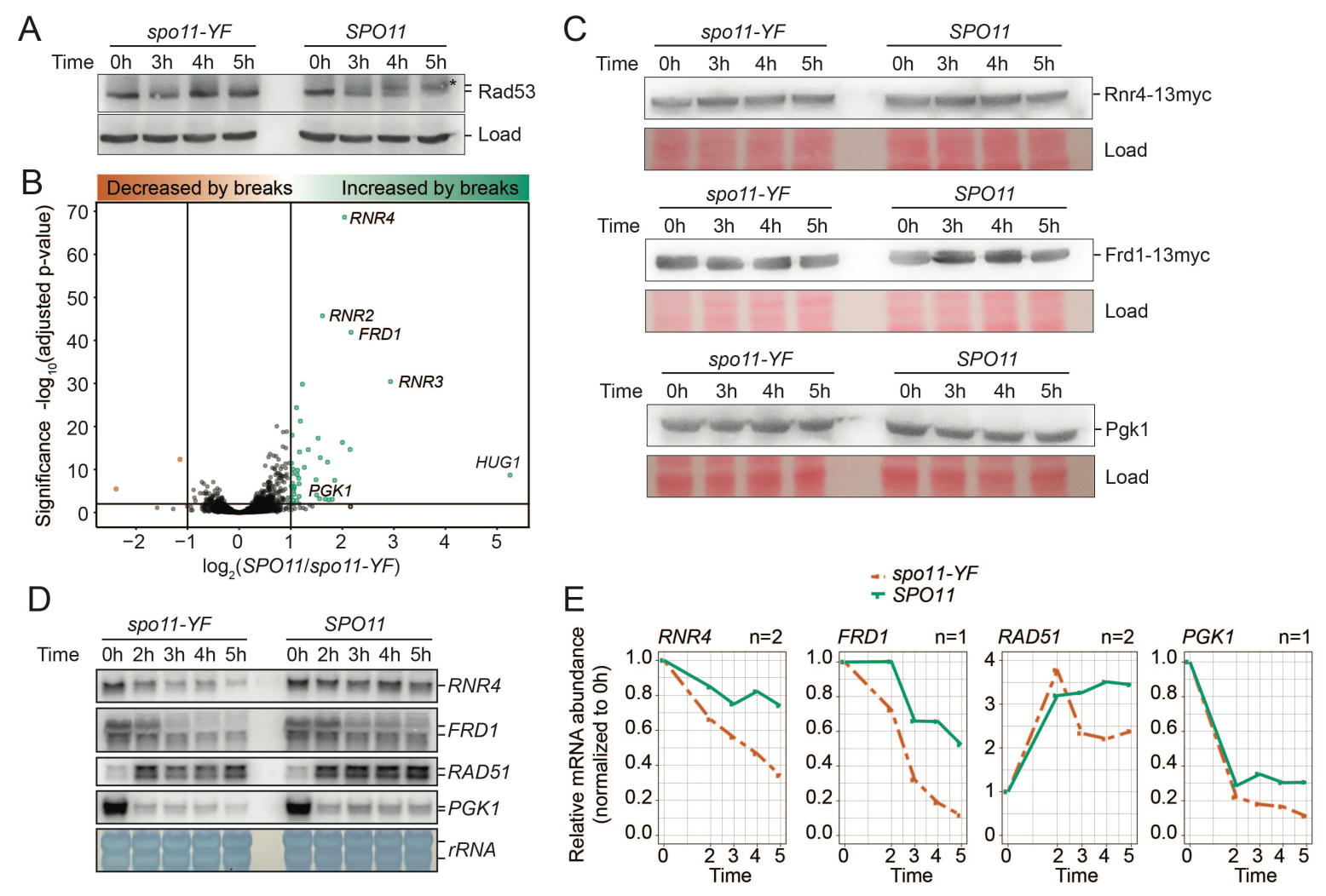

Kar et al., Figure 5

685 Figure 5: Activation of a transcriptional program in response to meiotic DNA breaks.

(A) Western blot analysis of Rad53 in spo11-YF cells and SPO11 cells. We used the mobility shift of Rad53 as a proxy for its phosphorylation and activation. A cross-reacting band produced by the Rad53 antibody was the loading control. Note: this analysis was performed on our experimental strains, which lack Pph3 phosphatase, resulting in more easily detectable Rad53 autophosphorylation than seen in strains with active Pph3 (Cartagena-Lirola et al., 2008; Falk et al., 2010).

(B) A volcano plot showing the results of mRNA-Seq analyses of spo11-YF cells and SPO11 cells. The $y$-axis shows - $\log _{10}$ (Benjamini \& Hochberg adjusted $p$-value) and the $x$-axis shows $\log _{2}$ fold change between SPO11 and spo11-YF. Each dot represents a gene.

(C) Western blot analysis of select transcriptionally induced genes. We used a 13xmyc tag to tag Rnr4 and Frd1 as antibodies for these genes were unavailable. Ponceau S staining of the membranes was the loading control.

(D) Northern blot analysis of select transcriptionally induced genes. RNR4, FRD1 and PGK1 were induced at the RNA level $>2$ fold in SPO11 cells compared to spo11-YF cells. $R A D 51$ was induced $\sim 1.6$ fold. Loading was normalized according to RNA concentrations measured after RNA extraction.

(E) Quantification of the Northern blots in (D) and additional replicate experiments. The plot shows the change of mRNA abundance compared to the 0-hour time point for each sample group (SPO11 or spo11-YF). For $n=2$ panels, we used the average of two 
bioRxiv preprint doi: https://doi.org/10.1101/2022.02.24 481857; this version posted February 25, 2022. The copyright holder for this preprint (which was not certified by peer review) is the author/funder, who has granted bioRxiv a license to display the preprint in perpetuity. It is made available under aCC-BY-NC-ND 4.0 International license. 


\section{Supplementary Figures}
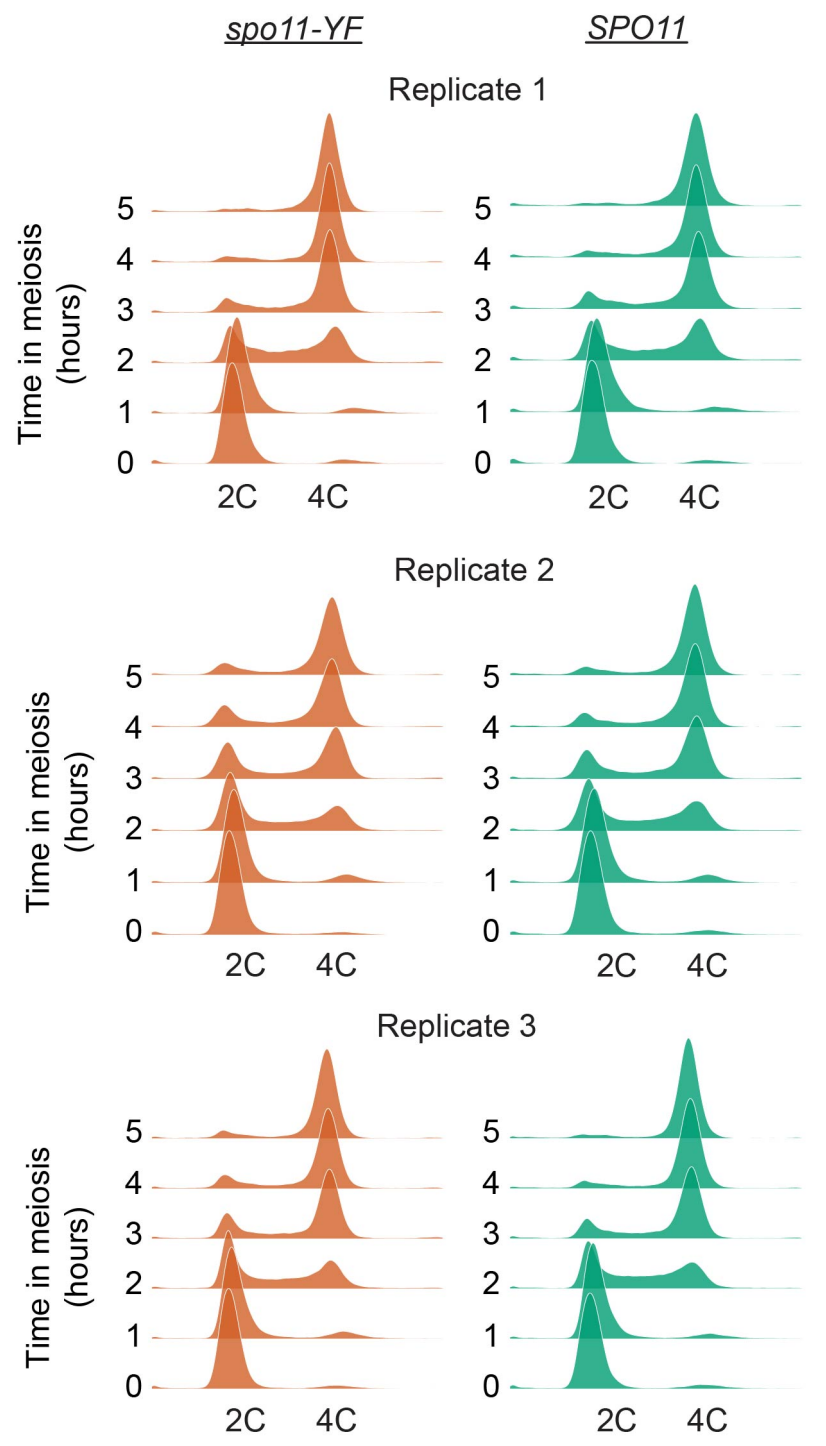

Kar et al., Supplemental Figure 1 
bioRxiv preprint doi: https://doi.org/10.1101/2022.02.24.481857; this version posted February 25, 2022. The copyright holder for this preprint (which was not certified by peer review) is the author/funder, who has granted bioRxiv a license to display the preprint in perpetuity. It is made available under aCC-BY-NC-ND 4.0 International license.

708 Figure S1: Synchrony of premeiotic DNA replication of biological replicates

709 We used DNA replication timing as a proxy for meiotic synchrony and meiotic 710 progression. Flow cytometry results using SYTOX Green are shown for all three 711 replicates. 
A

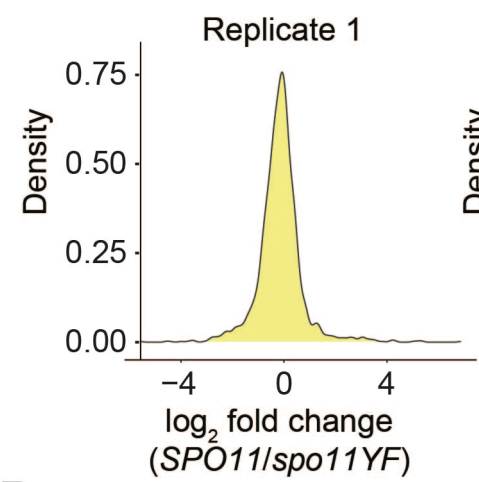

B

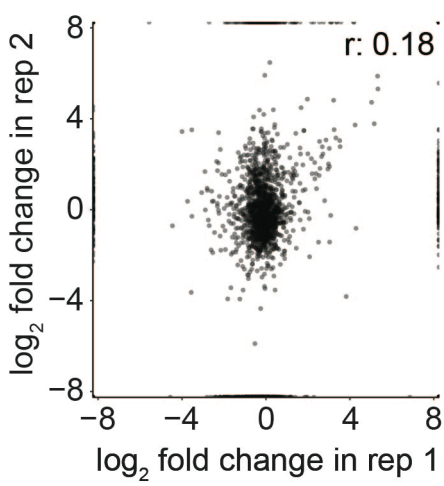

C

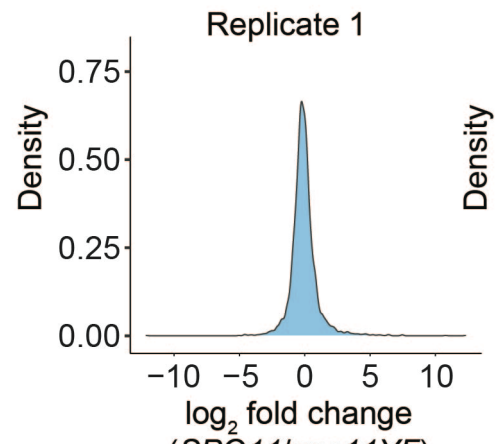

(SPO11/spo11YF)

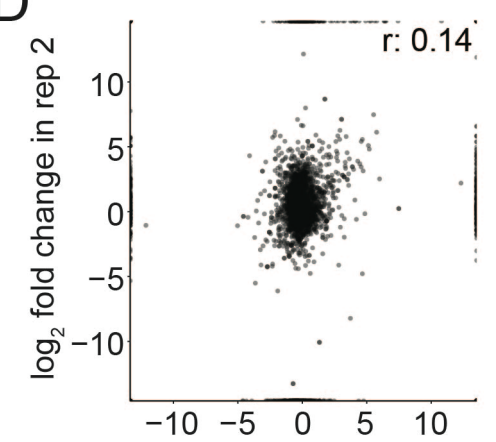

$\log _{2}$ fold change in rep 1
DDA
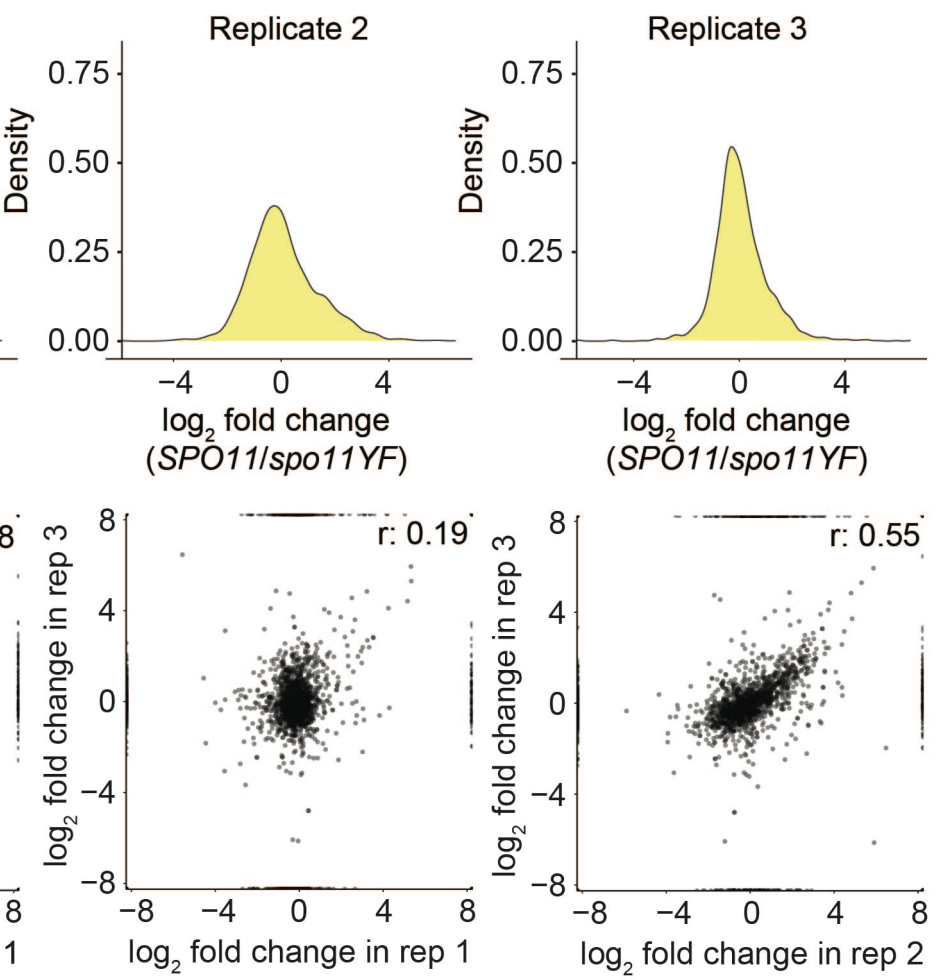

DIA
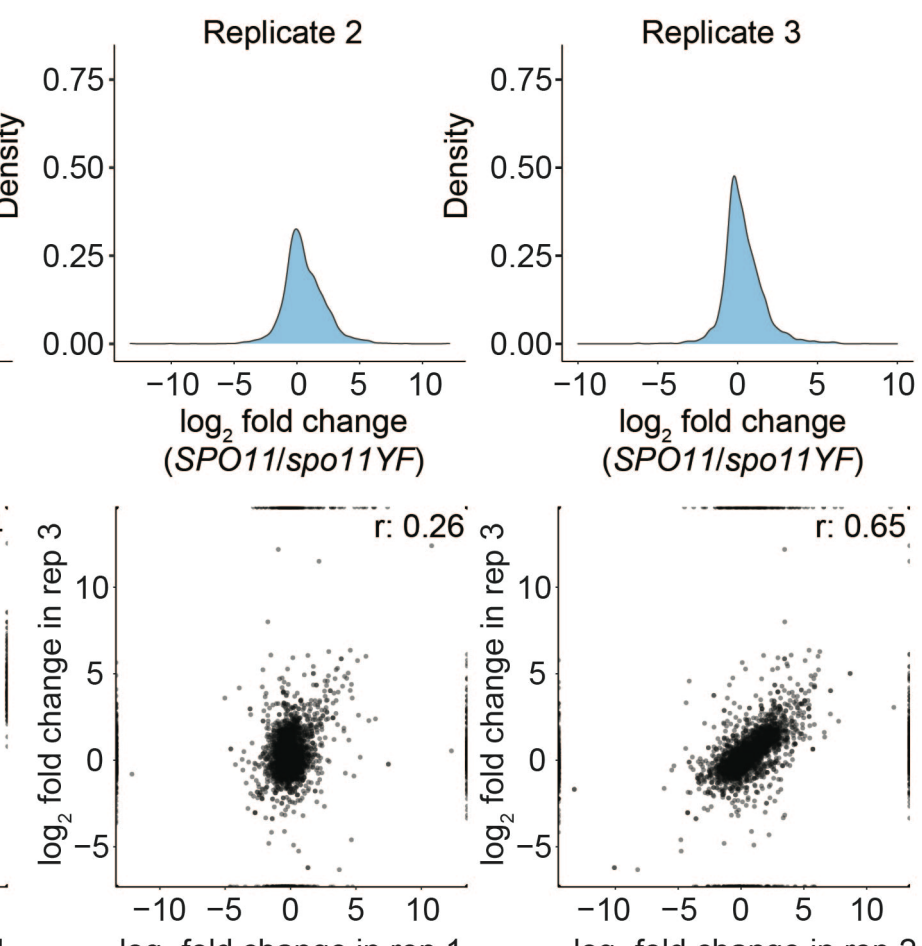

$\log _{2}$ fold change in rep 1

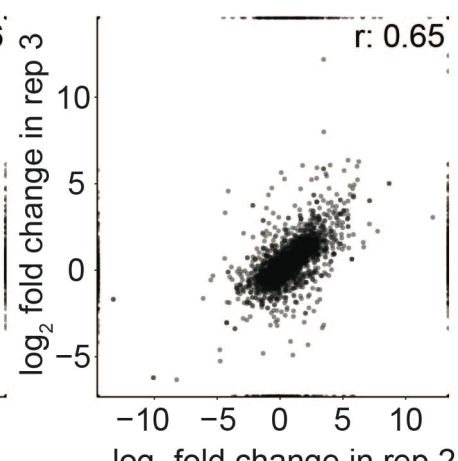

Kar et al., Supplemental Figure 2 
712 Figure S2: Assessment of DDA and DIA phosphoproteomics data

713 (A) Density plots for each replicate of the DDA phosphoproteomics dataset. $\log _{2}(S P O 11$ /spo11-YF) values are on the $x$-axis and density of the values are on the $y$-axis.

(B) Correlation of $\log _{2}(S P O 11 / s p o 11-Y F)$ values between each replicate is shown for DDA data, each dot represents a phosphosite.

(C) Density plots for each replicate of the DIA phosphoproteomics dataset. $\log _{2}(S P O 11$ /spo11-YF) values are on the $x$-axis and density of the values are on the $y$-axis.

(D) Correlation of $\log _{2}(S P 011 / s p 011-Y F)$ values between each replicate is shown for DIA data, each dot represents a phosphopeptide. 
A Phosphosites with larger than $0 \log _{2}$ fold change (SPO11/spo11YF) in replicate 1

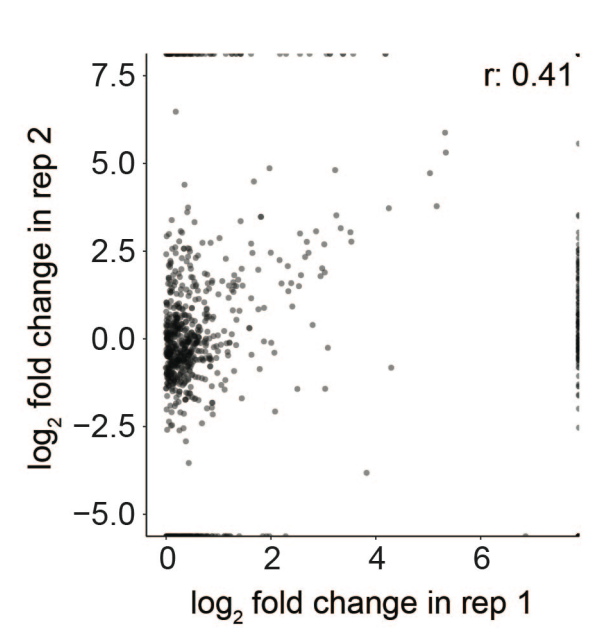

DDA

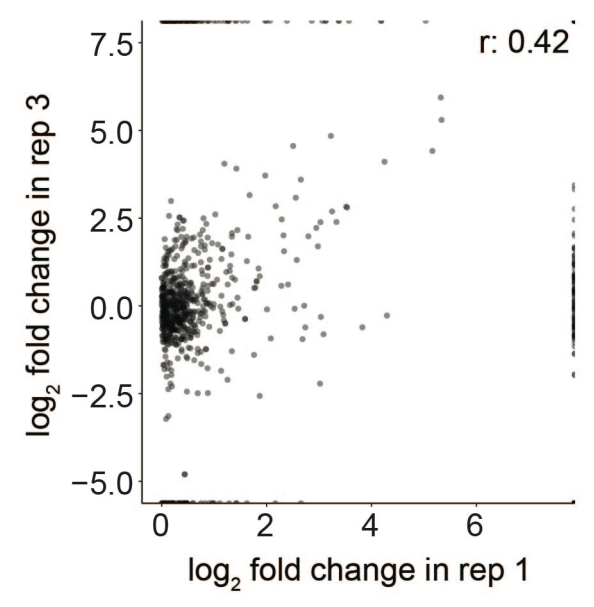

B

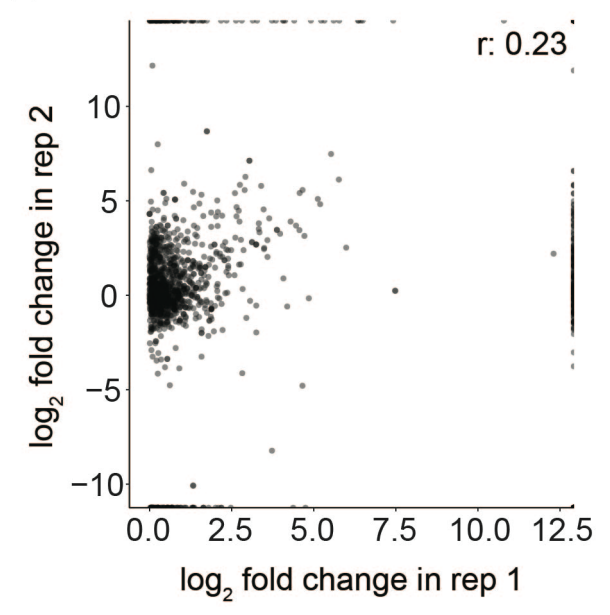

DIA

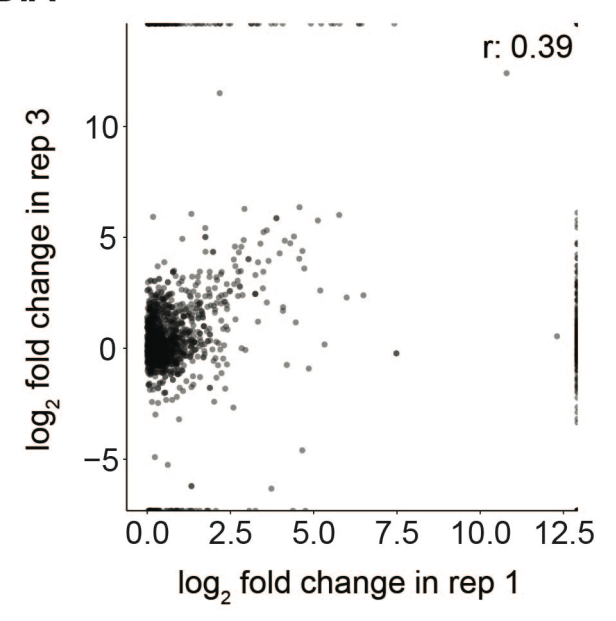

Kar et al., Supplemental Figure 3 
721 Figure S3: Further inspection of phosphoproteomics data from Replicate 1

722 (A) Correlation of $\log _{2}\left(S P O 11 /\right.$ spo11-YF) values only for phosphosites with a $\log _{2}(S P O 11$ /spo11-YF) value higher than 0 in replicate 1 is shown. These graphs are made using DDA data. Each dot represents a phosphosite.

725 (B) Same as A, but for DIA data. 
A

All detected phosphosites

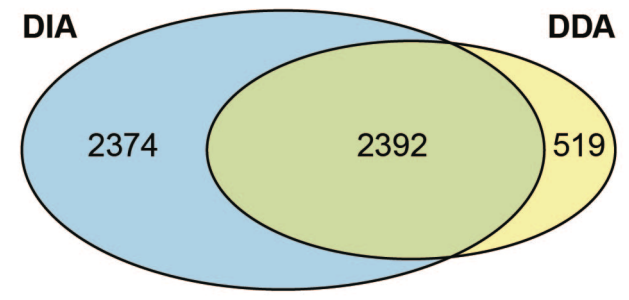

B

Break-dependent phopshosites

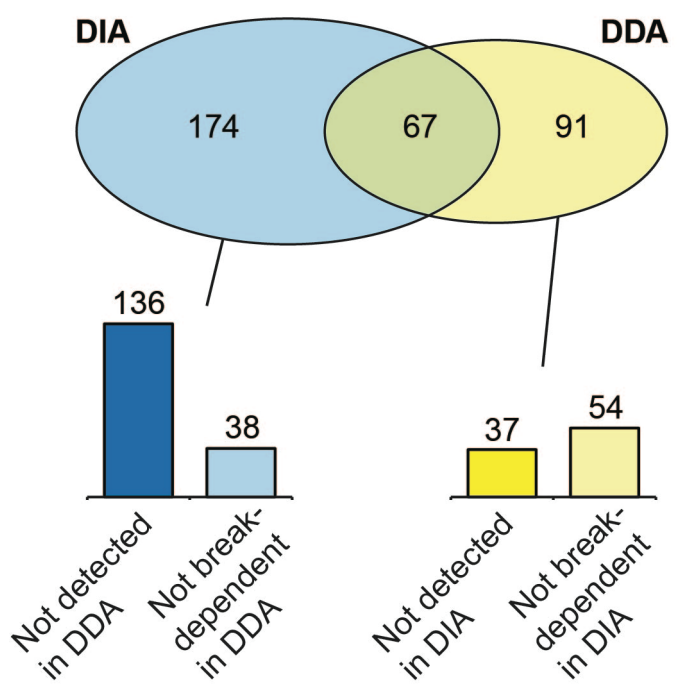

C Break-dependent only in DIA $(n=38)$

Break-dependent only in DDA $(n=54)$
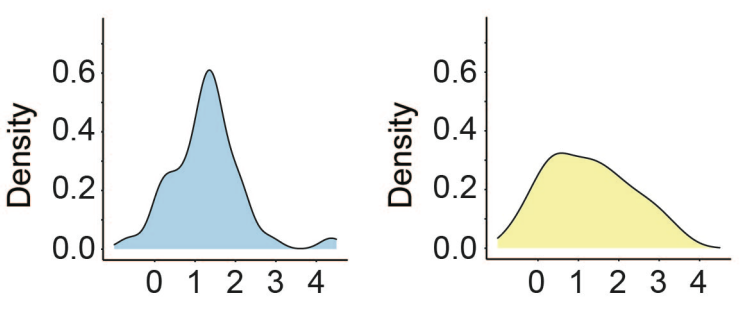

$\log _{2}$ fold change SPO11/spo11YF in DDA data

$\log _{2}$ fold change SPO11/spo11YF in DIA data

Kar et al., Supplemental Figure 4 
726 Figure S4: Differences and commonalities of DDA and DIA datasets

727 (A) A Venn diagram showing the overlap between DDA and DIA phosphosites for all phosphosites detected in at least 3 samples out of 6 in DDA or DIA datasets.

(B) Same as A, but for DNA break-dependent phosphosites. While 67 sites overlap between DDA and DIA, there are in total 265 method-specific sites. Closer inspection revealed that 136 of 174 DIA-specific DNA break-dependent sites were not reliably detected in the DDA data (not present in at least 3 samples out of 6 ), indicating that these sites are missing from the DDA data due to missing values. The remaining 38 DIA-specific sites were reliably detected in DDA data, but were not categorized as DNA break-dependent after differential presence analysis. Similarly, 37 of 91 DDA-specific sites were not detected reliably in the DIA data.

(C) The distribution of $\log _{2}$ fold changes (SPO11/spo11-YF) for 38 DIA-specific DNA breakdependent in the DDA data is between $\sim-0.6$ and $\sim 4.3$, and the distribution was centered around 1 (left panel). Only one site had a $\log _{2}$ fold change smaller than -0.5 $\left(\sim 1.4\right.$ fold decrease) while 31 sites had $\log _{2}$ fold changes larger than $0.5(\sim 1.4$ fold increase), indicating that these sites trended largely correctly but were below the significance cutoff in the DDA data. The 54 DDA-specific DNA break-dependent sites had a distribution of $\log _{2}$ fold changes between $\sim-0.7$ and $\sim 3.5$ in the DIA data, with the distribution being centered around 1 (right panel). While only one site had a $\log _{2}$ fold change smaller than -0.5 ( 1.4 fold decrease), 37 sites had $\log _{2}$ fold changes larger than $0.5\left(\sim 1.4\right.$ fold increase). Since a trend of being induced in response to DNA breaks $\left(\log _{2}\right.$ fold change $>0$ ) is observed for the majority of the method-specific sites, we merged all the DDA and DIA datasets. 
bioRxiv preprint doi: https://doi.org/10.1101/2022.02.24.481857; this version posted February 25, 2022. The copyright holder for this preprint (which was not certified by peer review) is the author/funder, who has granted bioRxiv a license to display the preprint in perpetuity. It is made available under aCC-BY-NC-ND 4.0 International license.

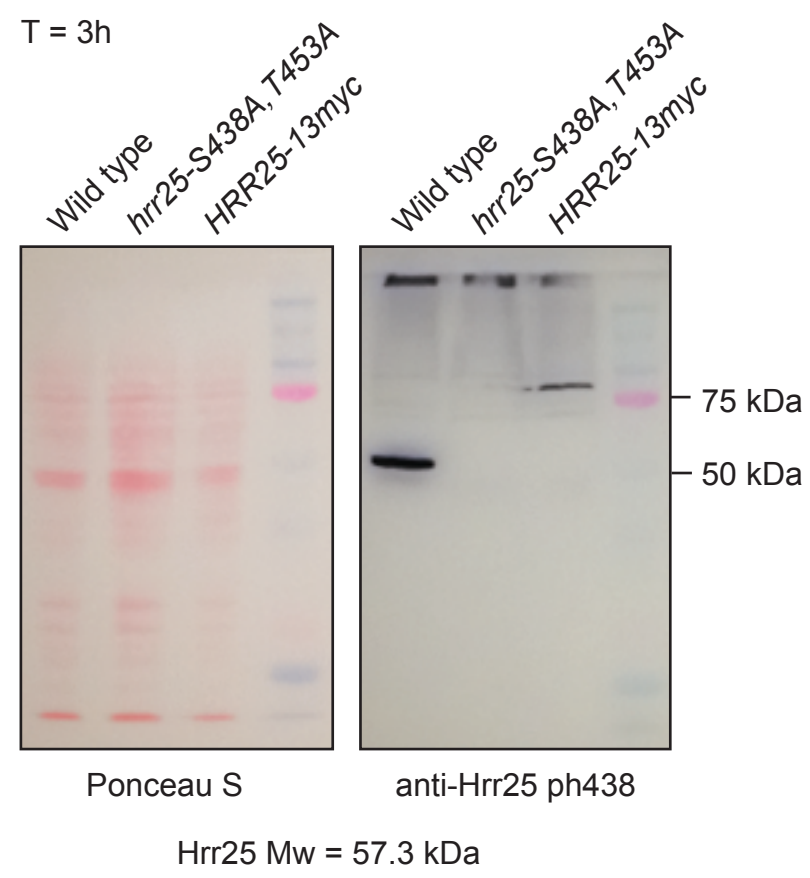

Kar et al., Supplemental Figure 5 
Figure S5: Specificity of Hrr25 phS438 antibody

(A) Western blot depicting the specificity of Hrr25 phS438 antibody. No signal was detected in non-phosphoryable S438A mutant, and a shift to a higher molecular weight was

A

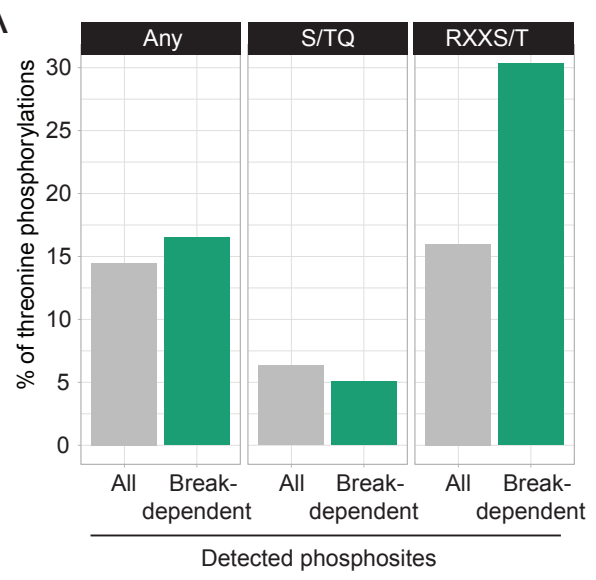

B

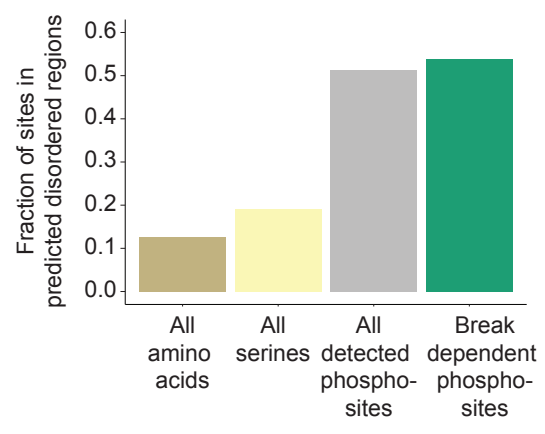

Kar et al., Supplemental Figure 6

\section{Figure S6: Other features of DNA break-dependent phosphosites}

754
(A) Bar graph showing enrichment of threonines as the phosphorylated amino acid in DNA break-dependent RxxS/T phosphorylation events, compared to all RxxS/T phosphorylation events detected in our data. No such effect is seen for DNA breakdependent $\underline{S / T Q}$ phosphorylation sites.

(B) Bar graph showing the fraction of the detected phosphorylation sites that localize to IUPRED predicted disordered regions larger than 30 amino acids. Fraction of all serines in the yeast proteome that localize to these regions and fraction of the proteome in these regions are also shown for comparison. 

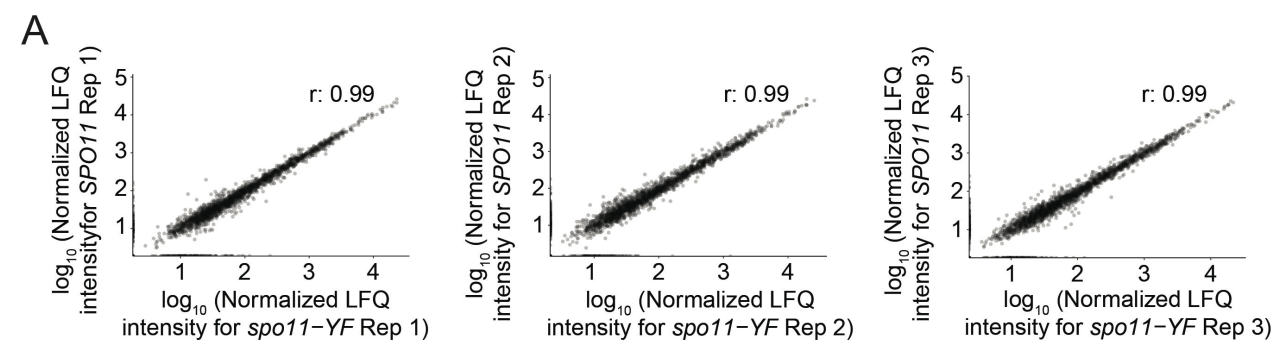

$\mathrm{B}$
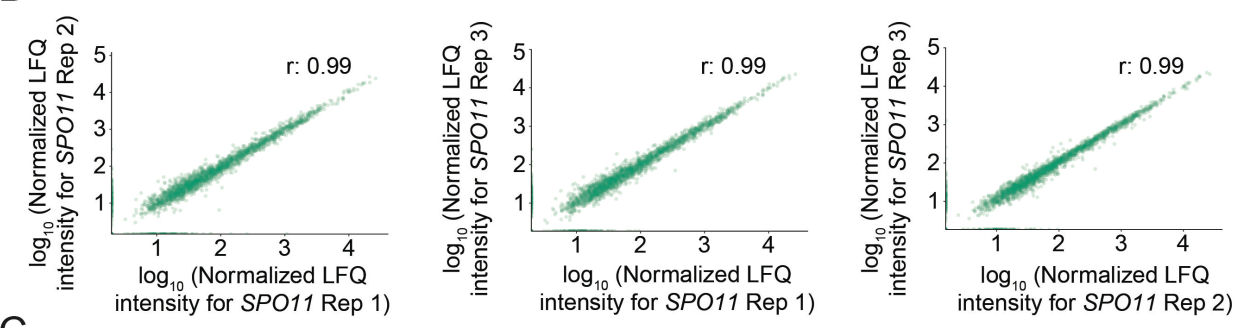

C
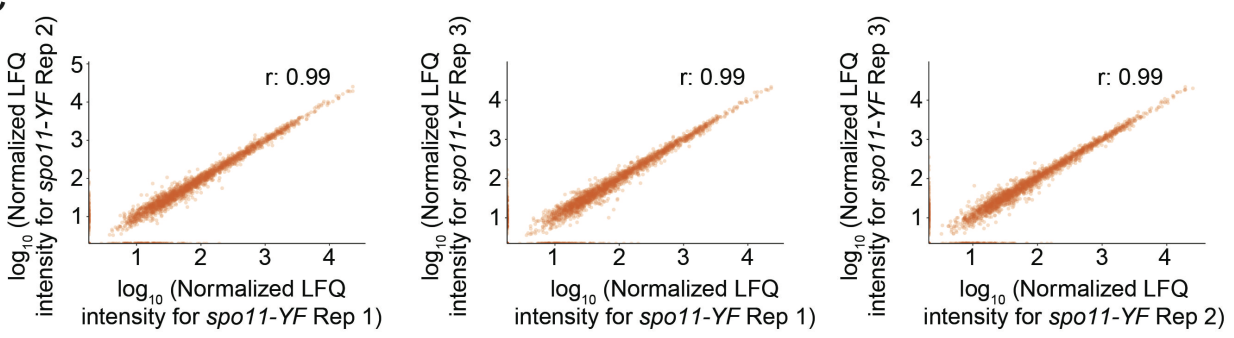

Kar et al., Supplemental Figure 7

(A) Scatter plots depicting the correlation between SPO11 and spo11-YF samples within each replicate groups.

(B) Scatter plots depicting the correlation of each SPO11 sample with other SPO11 replicate samples.

(C) Scatter plots depicting the correlation of each spo11-YF sample with other spo11-YF replicate samples. 


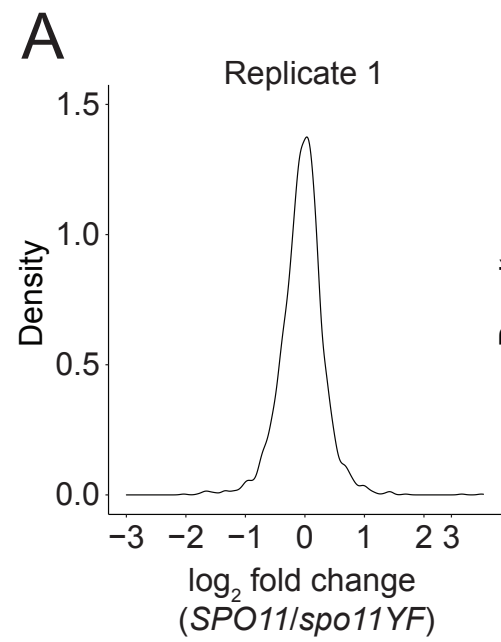

B

Proteins with present/absent break-dependent phosphosites in DDA data

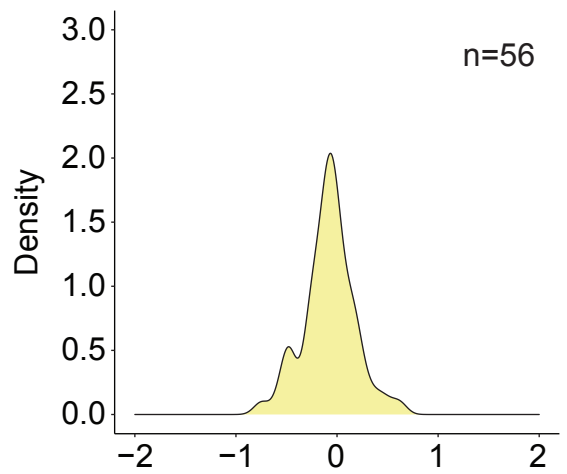

$\log _{2}$ fold change in protein levels (SP011/spo11YF)
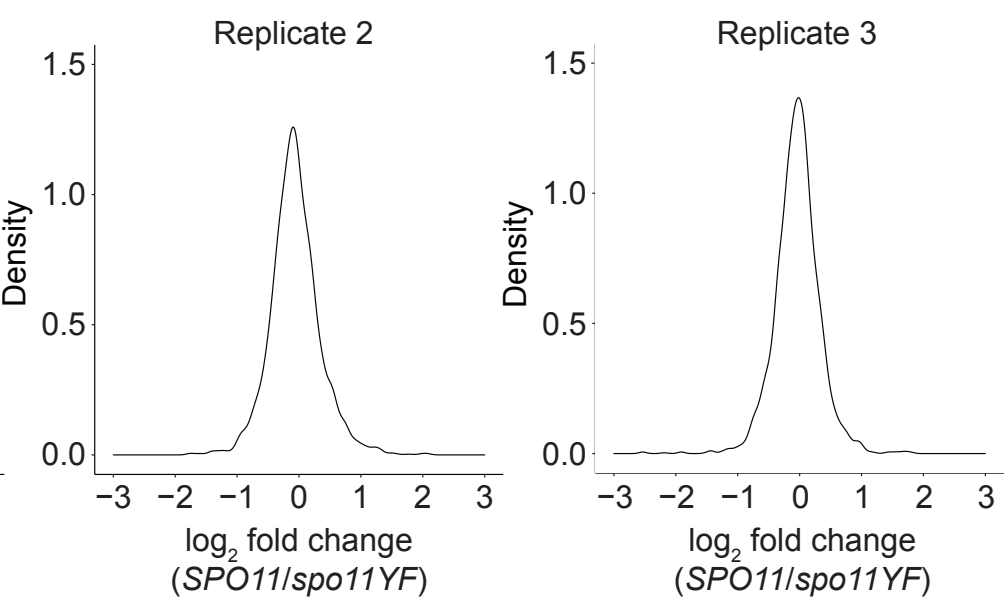

\section{Kar et al., Supplemental Figure 8}

Proteins with present/absent break-dependent phosphosites in DIA data

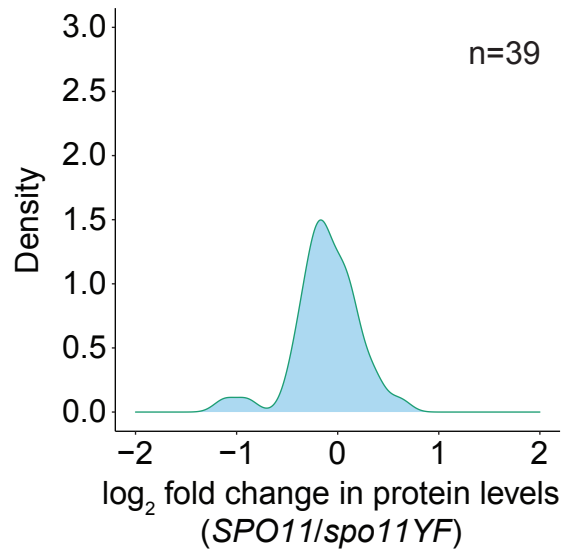


769 Figure S8: Distribution of protein level changes

770 (A) Density plots for each replicate in the proteomics dataset. $\log _{2}(S P O 11 /$ spo11-YF) values are on the $x$-axis and density of the values are on the $y$-axis.

772

(B) Density plots for proteins with qualitative (present/absent) DNA break-dependent sites in DDA data (left), and DIA data (right). 
bioRxiv preprint doi: https://doi.org/10.1101/2022.02.24.481857; this version posted February 25,2022 . The copyright holder for this preprint (which was not certified by peer review) is the author/funder, who has granted bioRxiv a license to display the preprint in perpetuity. It is made available under aCC-BY-NC-ND 4.0 International license.

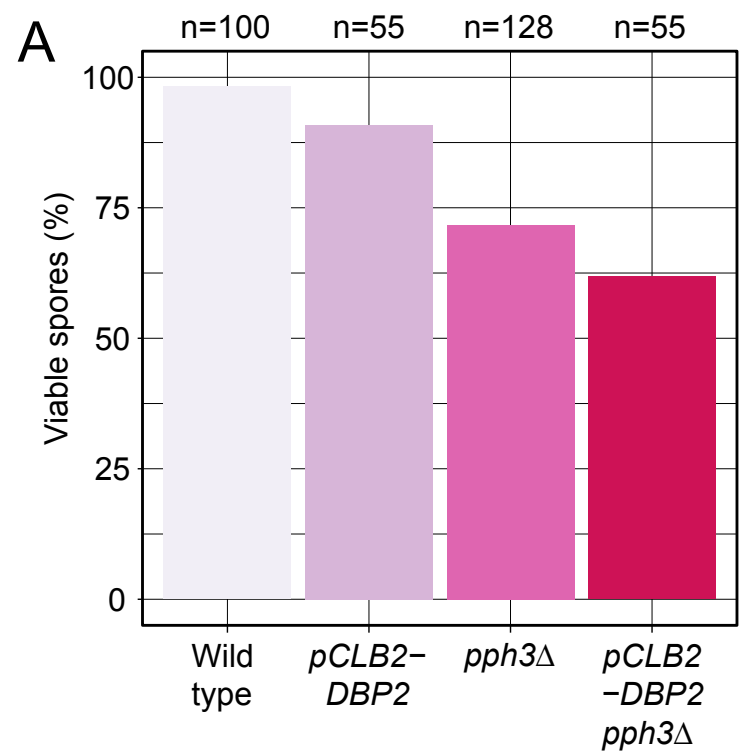

B
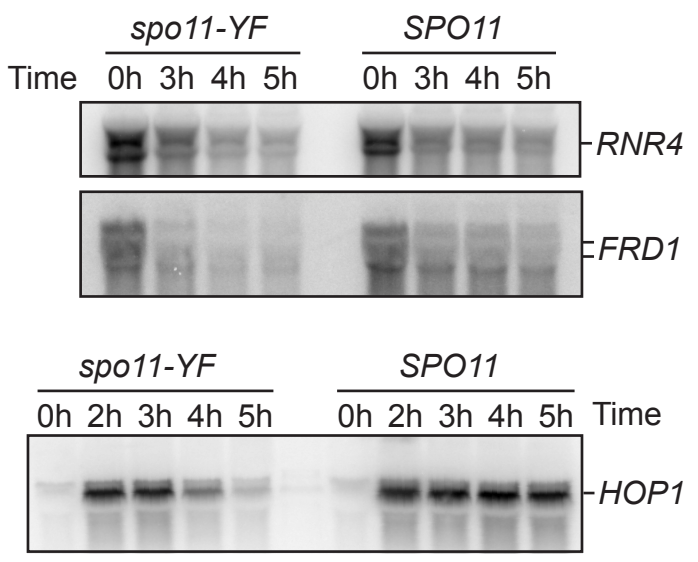

C

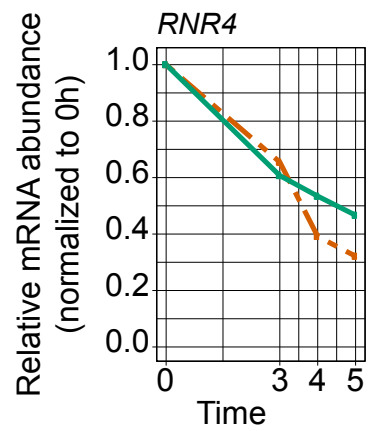

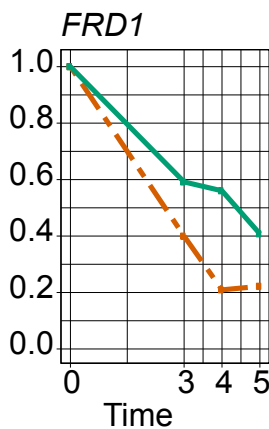

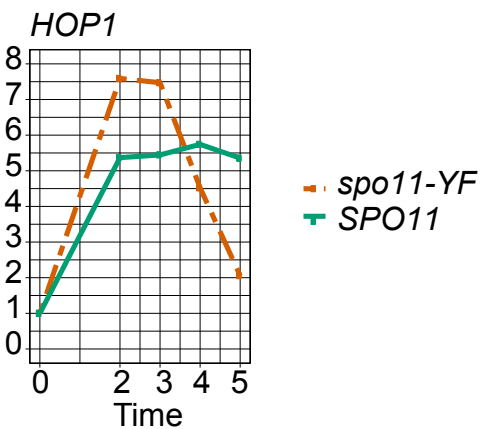

$\mathrm{D}$
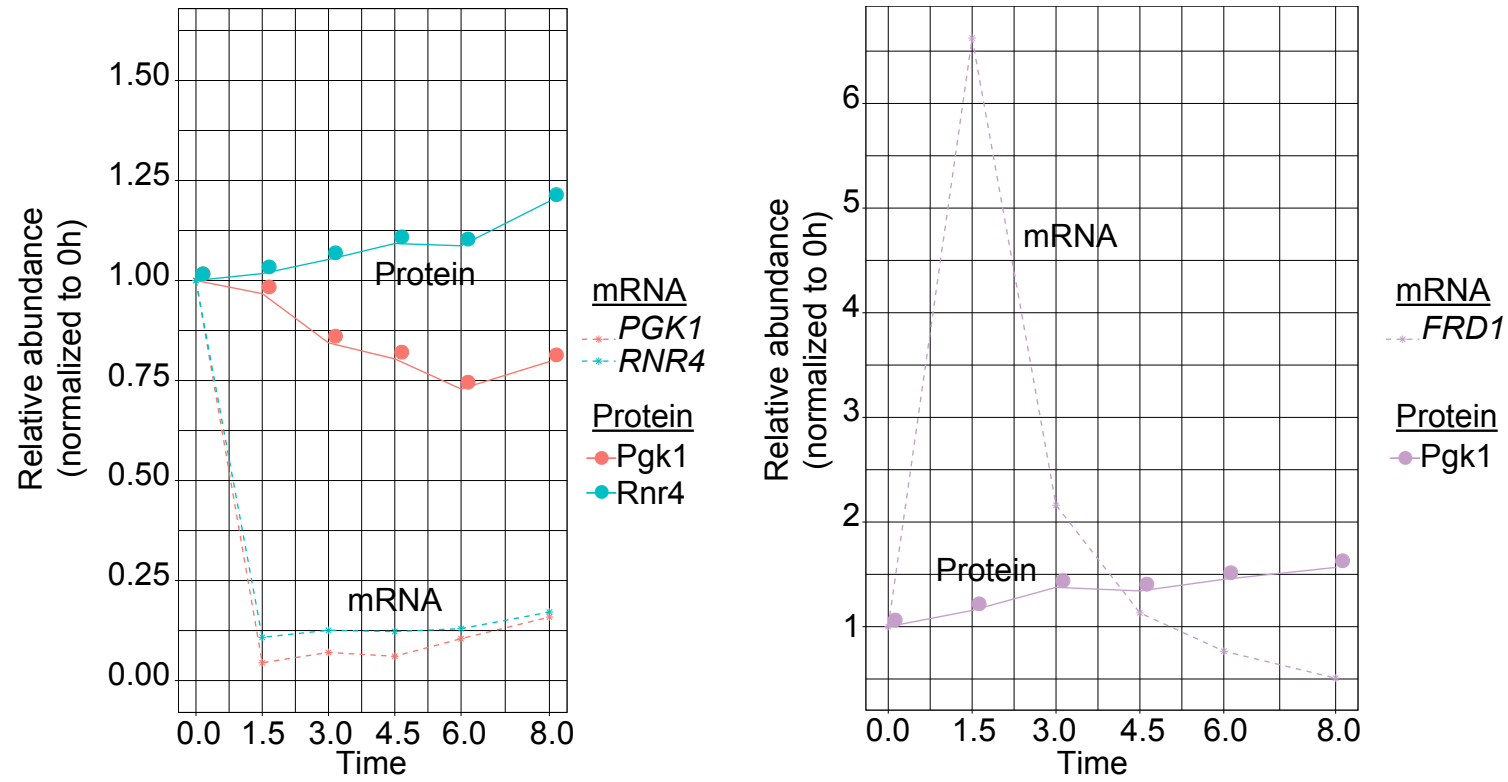

Kar et al., Supplemental Figure 9

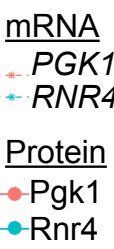

- Rnr4 
774 Figure S9: Effect of Dbp2 depletion on gamete viability, and dynamics of transcript and

775 protein levels during meiosis

776

777

778

779

780

781

782

783

784

785

786

787

788

\section{9}

790

791

792

793

794

795

796

797

798

799

800

801

(A) Bar graph showing spore viabilities for wild type, $p p h 3 \triangle, p C L B 2-D B P 2$, and $p p h 3 \triangle$ pCLB2-DBP2 strains.

(B) Northern blots for RNR4, FRD1 and HOP1 in SPO11 and spo11-YF cells. Loading is normalized based on number of cells (same culture volume is collected for all samples, $\mathrm{OD}=1.9)$.

(C) Quantification of the Northern blots in (B). Intensity values are normalized by dividing them to value at $0 \mathrm{~h}$.

(D) Left panel; change in RNR4 and PGK1 transcript and protein levels throughout meiosis compared to $0 \mathrm{~h}$ in wild-type cells, same for FRD1 on the right. FRD1 is plotted separately from $P G K 1$ and RNR4 due to the different scale of its y-axis. Data is from the Supplemental table 3 from (Cheng et al., 2018). We used the rpkm values from the indicated time points for plotting mRNA dynamics. For protein level changes, we used average of the two replicates from "total norm" columns.

\section{References}

Agarwala, S. D., Blitzblau, H. G., Hochwagen, A., \& Fink, G. R. (2012). RNA Methylation by the MIS Complex Regulates a Cell Fate Decision in Yeast. PLoS Genetics, 8(6), e1002732. https://doi.org/10.1371/journal.pgen.1002732

Andreson, B. L., Gupta, A., Georgieva, B. P., \& Rothstein, R. (2010). The ribonucleotide reductase inhibitor, Sml1, is sequentially phosphorylated, ubiquitylated and degraded in response to DNA damage. Nucleic Acids Research, 38(19), 6490-6501. https://doi.org/10.1093/nar/gkq552

Bailis, J. M., \& Roeder, G. S. (1998). Synaptonemal complex morphogenesis and sisterchromatid cohesion require Mek1-dependent phosphorylation of a meiotic chromosomal protein. Genes \& Development, 12(22), 3551-3563.

https://doi.org/10.1101/gad.12.22.3551 
Bartrand, A. J., Iyasu, D., Marinco, S. M., \& Brush, G. S. (2006). Evidence of Meiotic Crossover Control in Saccharomyces cerevisiae Through Mec1-Mediated Phosphorylation of Replication Protein A. Genetics, 172(1), 27-39. https://doi.org/10.1534/genetics.105.047845

Bashkirov, V. I., Bashkirova, E. V., Haghnazari, E., \& Heyer, W.-D. (2003). Direct Kinase-toKinase Signaling Mediated by the FHA Phosphoprotein Recognition Domain of the Dun1 DNA Damage Checkpoint Kinase. Molecular and Cellular Biology, 23(4), 1441-1452. https://doi.org/10.1128/MCB.23.4.1441-1452.2003

Basile, G., Aker, M., \& Mortimer, R. K. (1992). Nucleotide sequence and transcriptional

Baudat, F., Manova, K., Yuen, J. P., Jasin, M., \& Keeney, S. (2000). Chromosome Synapsis Defects and Sexually Dimorphic Meiotic Progression in Mice Lacking Spo11. Molecular Cell, 6(5), 989-998. https://doi.org/10.1016/S1097-2765(00)00098-8

Bekker-Jensen, D. B., Bernhardt, O. M., Hogrebe, A., Martinez-Val, A., Verbeke, L., Gandhi, T., Kelstrup, C. D., Reiter, L., \& Olsen, J. V. (2020). Rapid and site-specific deep phosphoproteome profiling by data-independent acquisition without the need for spectral libraries. Nature Communications, 11(1). https://doi.org/10.1038/s41467-020-14609-1 atypical topoisomerase II from archaea with implications for meiotic recombination. Nature, 386(6623), 414-417. https://doi.org/10.1038/386414a0

Bodi, Z., Button, J. D., Grierson, D., \& Fray, R. G. (2010). Yeast targets for mRNA methylation. Nucleic Acids Research, 38(16), 5327-5335. https://doi.org/10.1093/nar/gkq266

Bowman, G. D., \& Poirier, M. G. (2015). Post-Translational Modifications of Histones That Influence Nucleosome Dynamics. Chemical Reviews, 115(6), 2274-2295. https://doi.org/10.1021/cr500350x 
Bruderer, R., Bernhardt, O. M., Gandhi, T., Xuan, Y., Sondermann, J., Schmidt, M., GomezVarela, D., \& Reiter, L. (2017). Optimization of Experimental Parameters in DataIndependent Mass Spectrometry Significantly Increases Depth and Reproducibility of Results. Molecular \& Cellular Proteomics, 16(12), 2296-2309. https://doi.org/10.1074/mcp.RA117.000314

Bushkin, G. G., Pincus, D., Morgan, J. T., Richardson, K., Lewis, C., Chan, S. H., Bartel, D. P., \& Fink, G. R. (2019). M6A modification of a 3' UTR site reduces RME1 mRNA levels to promote meiosis. Nature Communications, 10(1), 3414. https://doi.org/10.1038/s41467-

Carballo, J. A., Johnson, A. L., Sedgwick, S. G., \& Cha, R. S. (2008). Phosphorylation of the Axial Element Protein Hop1 by Mec1/Tel1 Ensures Meiotic Interhomolog Recombination. Cell, 132(5), 758-770. https://doi.org/10.1016/j.cell.2008.01.035

Carballo, J. A., Panizza, S., Serrentino, M. E., Johnson, A. L., Geymonat, M., Borde, V., Klein, 019-11232-7

Callender, T. L., Laureau, R., Wan, L., Chen, X., Sandhu, R., Laljee, S., Zhou, S., Suhandynata, R. T., Prugar, E., Gaines, W. A., Kwon, Y., Börner, G. V., Nicolas, A., Neiman, A. M., \& Hollingsworth, N. M. (2016). Mek1 Down Regulates Rad51 Activity during Yeast Meiosis by Phosphorylation of Hed1. PLOS Genetics, 12(8), e1006226. F., \& Cha, R. S. (2013). Budding Yeast ATM/ATR Control Meiotic Double-Strand Break (DSB) Levels by Down-Regulating Rec114, an Essential Component of the DSBmachinery. PLoS Genetics, 9(6), e1003545. https://doi.org/10.1371/journal.pgen.1003545

Cartagena-Lirola, H., Guerini, I., Manfrini, N., Lucchini, G., \& Longhese, M. P. (2008). Role of the Saccharomyces cerevisiae Rad53 Checkpoint Kinase in Signaling Double-Strand Breaks during the Meiotic Cell Cycle. Molecular and Cellular Biology, 28(14), 44804493. https://doi.org/10.1128/MCB.00375-08 
854 Cartagena-Lirola, H., Guerini, I., Viscardi, V., Lucchini, G., \& Longhese, M. P. (2006). Budding

Yeast Sae2 is an In Vivo Target of the Mec1 and Tel1 Checkpoint Kinases During Meiosis. Cell Cycle, 5(14), 1549-1559. https://doi.org/10.4161/cc.5.14.2916

Chen, S., Smolka, M. B., \& Zhou, H. (2007). Mechanism of Dun1 Activation by Rad53 Phosphorylation in Saccharomyces cerevisiae. Journal of Biological Chemistry, 282(2), 986-995. https://doi.org/10.1074/jbc.M609322200 Hollingsworth, N. M. (2018). Mek1 coordinates meiotic progression with DNA break repair by directly phosphorylating and inhibiting the yeast pachytene exit regulator H.-C., Miller, D. E., Zhou, H., Börner, G. V., \& Hollingsworth, N. M. (2015). Ndt80. PLOS Genetics, 14(11), e1007832. https://doi.org/10.1371/journal.pgen.1007832

Chen, X., Niu, H., Chung, W.-H., Zhu, Z., Papusha, A., Shim, E. Y., Lee, S. E., Sung, P., \& Ira, Phosphorylation of the Synaptonemal Complex Protein Zip1 Regulates the Crossover/Noncrossover Decision during Yeast Meiosis. PLOS Biology, 13(12), e1002329. https://doi.org/10.1371/journal.pbio.1002329

Cheng, Z., Otto, G. M., Powers, E. N., Keskin, A., Mertins, P., Carr, S. A., Jovanovic, M., \& Brar, G. A. (2018). Pervasive, Coordinated Protein-Level Changes Driven by Transcript Isoform Switching during Meiosis. Cell, 172(5), 910-923.e16. https://doi.org/10.1016/j.cell.2018.01.035

Clancy, M. J. (2002). Induction of sporulation in Saccharomyces cerevisiae leads to the formation of N6-methyladenosine in mRNA: A potential mechanism for the activity of the 
IME4 gene. Nucleic Acids Research, 30(20), 4509-4518. https://doi.org/10.1093/nar/gkf573

Cobb, J. A., Schleker, T., Rojas, V., Bjergbaek, L., Tercero, J. A., \& Gasser, S. M. (2005).

de los Santos, T., \& Hollingsworth, N. M. (1999). Red1p, a MEK1-dependent Phosphoprotein That Physically Interacts with Hop1p during Meiosis in Yeast. Journal of Biological Chemistry, 274(3), 1783-1790. https://doi.org/10.1074/jbc.274.3.1783

Domon, B., \& Aebersold, R. (2010). Options and considerations when selecting a quantitative proteomics strategy. Nature Biotechnology, 28(7), 710-721. https://doi.org/10.1038/nbt.1661

Downs, J. A., Lowndes, N. F., \& Jackson, S. P. (2000). A role for Saccharomyces cerevisiae histone H2A in DNA repair. Nature, 408(6815), 1001-1004. https://doi.org/10.1038/35050000

894 Elledge, S. J., \& Davis, R. W. (1987). Identification and isolation of the gene encoding the small subunit of ribonucleotide reductase from Saccharomyces cerevisiae: DNA damageinducible gene required for mitotic viability. Molecular and Cellular Biology, 7(8), 27832793. https://doi.org/10.1128/mcb.7.8.2783-2793.1987

Elledge, S. J., \& Davis, R. W. (1990). Two genes differentially regulated in the cell cycle and by DNA-damaging agents encode alternative regulatory subunits of ribonucleotide

901 Ewels, P. A., Peltzer, A., Fillinger, S., Patel, H., Alneberg, J., Wilm, A., Garcia, M. U., Di

902 Tommaso, P., \& Nahnsen, S. (2020). The nf-core framework for community-curated 903 bioinformatics pipelines. Nature Biotechnology, 38(3), 276-278.

904 https://doi.org/10.1038/s41587-020-0439-x 
Falk, J. E., Chan, A. C., Hoffmann, E., \& Hochwagen, A. (2010). A Mec1- and PP4-Dependent Checkpoint Couples Centromere Pairing to Meiotic Recombination. Developmental Cell, 19(4), 599-611. https://doi.org/10.1016/j.devcel.2010.09.006

Garcia, V., Gray, S., Allison, R. M., Cooper, T. J., \& Neale, M. J. (2015). Tel1ATM-mediated interference suppresses clustered meiotic double-strand-break formation. Nature, 520(7545), 114-118. https://doi.org/10.1038/nature13993

Gasch, A. P., Huang, M., Metzner, S., Botstein, D., Elledge, S. J., \& Brown, P. O. (2001). Genomic Expression Responses to DNA-damaging Agents and the Regulatory Role of the Yeast ATR Homolog Mec1p. Molecular Biology of the Cell, 12(10), 2987-3003.

Harshil Patel, Ewels, P., Peltzer, A., Hammarén, R., Botvinnik, O., Sturm, G., Moreno, D., Pranathi Vemuri, Silviamorins, Pantano, L., FriederikeHanssen, Garcia, M. U., Rfenouil, Marchoeppner, Zhou, P., Gabernet, G., Straub, D., Sven, F., Nf-Core Bot, ... Davenport,

He, W., Rao, H. B. D. P., Tang, S., Bhagwat, N., Kulkarni, D. S., Ma, Y., Chang, M. A. W., Hall, C. (2021). nf-core/rnaseq: Nf-core/rnaseq v3.1 - Lead Alligator (3.1) [Computer software]. Zenodo. https://doi.org/10.5281/ZENODO.4757022

Holt, L. J., Tuch, B. B., Villen, J., Johnson, A. D., Gygi, S. P., \& Morgan, D. O. (2009). Global Analysis of Cdk1 Substrate Phosphorylation Sites Provides Insights into Evolution.

928 Huang, M., \& Elledge, S. J. (1997). Identification of RNR4, encoding a second essential small subunit of ribonucleotide reductase in Saccharomyces cerevisiae. Molecular and Cellular Biology, 17(10), 6105-6113. https://doi.org/10.1128/MCB.17.10.6105 
931 Huang, M., Zhou, Z., \& Elledge, S. J. (1998). The DNA Replication and Damage Checkpoint Pathways Induce Transcription by Inhibition of the Crt1 Repressor. Cell, 94(5), 595-605. https://doi.org/10.1016/S0092-8674(00)81601-3

934 Hustedt, N., Seeber, A., Sack, R., Tsai-Pflugfelder, M., Bhullar, B., Vlaming, H., van Leeuwen, F., Guénolé, A., van Attikum, H., Srivas, R., Ideker, T., Shimada, K., \& Gasser, S. M. (2015). Yeast PP4 Interacts with ATR Homolog Ddc2-Mec1 and Regulates Checkpoint Signaling. Molecular Cell, 57(2), 273-289. https://doi.org/10.1016/j.molcel.2014.11.016

Jaehnig, E. J., Kuo, D., Hombauer, H., Ideker, T. G., \& Kolodner, R. D. (2013). Checkpoint Kinases Regulate a Global Network of Transcription Factors in Response to DNA

Kar, F. M., \& Hochwagen, A. (2021). Phospho-Regulation of Meiotic Prophase. Frontiers in Cell and Developmental Biology, 9, 667073. https://doi.org/10.3389/fcell.2021.667073

Keeney, S. (2001). Mechanism and control of meiotic recombination initiation. In Current Topics in Developmental Biology (Vol. 52, pp. 1-53). Elsevier. https://doi.org/10.1016/S00702153(01)52008-6

Keeney, S., Giroux, C. N., \& Kleckner, N. (1997). Meiosis-Specific DNA Double-Strand Breaks Are Catalyzed by Spo11, a Member of a Widely Conserved Protein Family. Cell, 88(3), 375-384. https://doi.org/10.1016/S0092-8674(00)81876-0

Keogh, M.-C., Kim, J.-A., Downey, M., Fillingham, J., Chowdhury, D., Harrison, J. C., Onishi, M.,

954 Kitata, R. B., Choong, W.-K., Tsai, C.-F., Lin, P.-Y., Chen, B.-S., Chang, Y.-C., Nesvizhskii, A. Datta, N., Galicia, S., Emili, A., Lieberman, J., Shen, X., Buratowski, S., Haber, J. E., Durocher, D., Greenblatt, J. F., \& Krogan, N. J. (2006). A phosphatase complex that dephosphorylates $\mathrm{yH} 2 \mathrm{AX}$ regulates DNA damage checkpoint recovery. Nature, 439(7075), 497-501. https://doi.org/10.1038/nature04384 I., Sung, T.-Y., \& Chen, Y.-J. (2021). A data-independent acquisition-based global 
phosphoproteomics system enables deep profiling. Nature Communications, 12(1), 2539. https://doi.org/10.1038/s41467-021-22759-z

Klapholz, S., Waddell, C. S., \& Esposito, R. E. (1985). THE ROLE OF THE SPO11 GENE IN MEIOTIC RECOMBINATION IN YEAST. Genetics, 110(2), 187-216. https://doi.org/10.1093/genetics/110.2.187

Kniewel, R., Murakami, H., Liu, Y., Ito, M., Ohta, K., Hollingsworth, N. M., \& Keeney, S. (2017). Histone H3 Threonine 11 Phosphorylation Is Catalyzed Directly by the Meiosis-Specific Kinase Mek1 and Provides a Molecular Readout of Mek1 Activity in Vivo. Genetics, 207(4), 1313-1333. https://doi.org/10.1534/genetics.117.300359

Kwon, Y. T., Xia, Z., An, J. Y., Tasaki, T., Davydov, I. V., Seo, J. W., Sheng, J., Xie, Y., \& Varshavsky, A. (2003). Female Lethality and Apoptosis of Spermatocytes in Mice Lacking the UBR2 Ubiquitin Ligase of the N-End Rule Pathway. Molecular and Cellular

Lai, Y.-J., Lin, F.-M., Chuang, M.-J., Shen, H.-J., \& Wang, T.-F. (2011). Genetic Requirements and Meiotic Function of Phosphorylation of the Yeast Axial Element Protein Red1. Molecular and Cellular Biology, 31(5), 912-923. https://doi.org/10.1128/MCB.00895-10

972 Lam, I., \& Keeney, S. (2015). Mechanism and Regulation of Meiotic Recombination Initiation. Cold Spring Harbor Perspectives in Biology, 7(1), a016634. https://doi.org/10.1101/cshperspect.a016634

975 Lao, J. P., Ulrich, K. M., Johnson, J. R., Newton, B. W., Vashisht, A. A., Wohlschlegel, J. A., Krogan, N. J., \& Toczyski, D. P. (2018). The Yeast DNA Damage Checkpoint Kinase Rad53 Targets the Exoribonuclease, Xrn1. G3 Genes|Genomes|Genetics, 8(12), 3931dispersion for RNA-seq data with DESeq2. Genome Biology, 15(12), 550. https://doi.org/10.1186/s13059-014-0550-8 
MacQueen, A. J., \& Hochwagen, A. (2011). Checkpoint mechanisms: The puppet masters of meiotic prophase. Trends in Cell Biology, 21(7), 393-400. https://doi.org/10.1016/j.tcb.2011.03.004

MacQueen, A. J., \& Roeder, G. S. (2009). Fpr3 and Zip3 Ensure that Initiation of Meiotic Recombination Precedes Chromosome Synapsis in Budding Yeast. Current Biology, 19(18), 1519-1526. https://doi.org/10.1016/j.cub.2009.08.048

Mangan, S., \& Alon, U. (2003). Structure and function of the feed-forward loop network motif. Proceedings of the National Academy of Sciences, 100(21), 11980-11985.

Martin-Perez, M., \& Villén, J. (2017). Determinants and Regulation of Protein Turnover in Yeast. Cell Systems, 5(3), 283-294.e5. https://doi.org/10.1016/j.cels.2017.08.008

McCord, R., Pierce, M., Xie, J., Wonkatal, S., Mickel, C., \& Vershon, A. K. (2003). Rfm1, a Novel Tethering Factor Required To Recruit the Hst1 Histone Deacetylase for Repression of Middle Sporulation Genes. Molecular and Cellular Biology, 23(6), 2009_ 2016. https://doi.org/10.1128/MCB.23.6.2009-2016.2003 in Single Shotgun Proteomics Runs but the Majority is Inaccessible to Data-Dependent LC-MS/MS. Journal of Proteome Research, 10(4), 1785-1793. https://doi.org/10.1021/pr101060v 
Phosphorylation Site Motifs. Science Signaling, 3(109), ra12-ra12. https://doi.org/10.1126/scisignal.2000482

Niu, H., Wan, L., Busygina, V., Kwon, Y., Allen, J. A., Li, X., Kunz, R. C., Kubota, K., Wang, B.,

Okaz, E., Argüello-Miranda, O., Bogdanova, A., Vinod, P. K., Lipp, J. J., Markova, Z., Zagoriy, I., Novak, B., \& Zachariae, W. (2012). Meiotic Prophase Requires Proteolysis of M Phase

O’Neill, T., Dwyer, A. J., Ziv, Y., Chan, D. W., Lees-Miller, S. P., Abraham, R. H., Lai, J. H., Hill, D., Shiloh, Y., Cantley, L. C., \& Rathbun, G. A. (2000). Utilization of Oriented Peptide Libraries to Identify Substrate Motifs Selected by ATM. Journal of Biological Chemistry, 275(30), 22719-22727. https://doi.org/10.1074/jbc.M001002200

Parkhomchuk, D., Borodina, T., Amstislavskiy, V., Banaru, M., Hallen, L., Krobitsch, S., sequencing of complementary DNA. Nucleic Acids Research, 37(18), e123-e123. https://doi.org/10.1093/nar/gkp596

Penedos, A., Johnson, A. L., Strong, E., Goldman, A. S., Carballo, J. A., \& Cha, R. S. (2015). Essential and Checkpoint Functions of Budding Yeast ATM and ATR during Meiotic Prophase Are Facilitated by Differential Phosphorylation of a Meiotic Adaptor Protein, Hop1. PLOS ONE, 10(7), e0134297. https://doi.org/10.1371/journal.pone.0134297

Ritchie, M. E., Phipson, B., Wu, D., Hu, Y., Law, C. W., Shi, W., \& Smyth, G. K. (2015). Limma powers differential expression analyses for RNA-sequencing and microarray studies. Nucleic Acids Research, 43(7), e47-e47. https://doi.org/10.1093/nar/gkv007 
Romanienko, P. J., \& Camerini-Otero, R. D. (2000). The Mouse Spo11 Gene Is Required for Meiotic Chromosome Synapsis. Molecular Cell, 6(5), 975-987. https://doi.org/10.1016/S1097-2765(00)00097-6

San-Segundo, P. A., \& Roeder, G. S. (1999). Pch2 Links Chromatin Silencing to Meiotic Checkpoint Control. Cell, 97(3), 313-324. https://doi.org/10.1016/S0092-8674(00)80741-

Schubert, O. T., Gillet, L. C., Collins, B. C., Navarro, P., Rosenberger, G., Wolski, W. E., Lam, H., Amodei, D., Mallick, P., MacLean, B., \& Aebersold, R. (2015). Building high-quality assay libraries for targeted analysis of SWATH MS data. Nature Protocols, 10(3), 426-

Schwartz, S., Agarwala, S. D., Mumbach, M. R., Jovanovic, M., Mertins, P., Shishkin, A., Tabach, Y., Mikkelsen, T. S., Satija, R., Ruvkun, G., Carr, S. A., Lander, E. S., Fink, G. R., \& Regev, A. (2013). High-Resolution Mapping Reveals a Conserved, Widespread, Dynamic mRNA Methylation Program in Yeast Meiosis. Cell, 155(6), 1409-1421. https://doi.org/10.1016/j.cell.2013.10.047

Selevsek, N., Chang, C.-Y., Gillet, L. C., Navarro, P., Bernhardt, O. M., Reiter, L., Cheng, L.-Y., Vitek, O., \& Aebersold, R. (2015). Reproducible and Consistent Quantification of the Saccharomyces cerevisiae Proteome by SWATH-mass spectrometry. Molecular \& Cellular Proteomics, 14(3), 739-749. https://doi.org/10.1074/mcp.M113.035550

Serrentino, M.-E., Chaplais, E., Sommermeyer, V., \& Borde, V. (2013). Differential Association of the Conserved SUMO Ligase Zip3 with Meiotic Double-Strand Break Sites Reveals Regional Variations in the Outcome of Meiotic Recombination. PLoS Genetics, 9(4), e1003416. https://doi.org/10.1371/journal.pgen.1003416

Shah, J. C., \& Clancy, M. J. (1992). IME4, a gene that mediates MAT and nutritional control of meiosis in Saccharomyces cerevisiae. Molecular and Cellular Biology, 12(3), 10781086. https://doi.org/10.1128/MCB.12.3.1078 
Shroff, R., Arbel-Eden, A., Pilch, D., Ira, G., Bonner, W. M., Petrini, J. H., Haber, J. E., \& Lichten, M. (2004). Distribution and Dynamics of Chromatin Modification Induced by a Defined DNA Double-Strand Break. Current Biology, 14(19), 1703-1711. https://doi.org/10.1016/j.cub.2004.09.047

Smolka, M. B., Albuquerque, C. P., Chen, S. -h., \& Zhou, H. (2007). Proteome-wide identification of in vivo targets of DNA damage checkpoint kinases. Proceedings of the National Academy of Sciences, 104(25), 10364-10369. https://doi.org/10.1073/pnas.0701622104

Subramanian, V. V., \& Hochwagen, A. (2014). The Meiotic Checkpoint Network: Step-by-Step

Subramanian, V. V., Zhu, X., Markowitz, T. E., Vale-Silva, L. A., San-Segundo, P. A., Hollingsworth, N. M., Keeney, S., \& Hochwagen, A. (2019). Persistent DNA-break potential near telomeres increases initiation of meiotic recombination on short chromosomes. Nature Communications, 10(1), 970. https://doi.org/10.1038/s41467-01908875-x Mek1 Substrates during Meiosis in Saccharomyces cerevisiae Using Quantitative Phosphoproteomics. PLOS ONE, 11(5), e0155931. https://doi.org/10.1371/journal.pone.0155931

Swaney, D. L., Wenger, C. D., \& Coon, J. J. (2010). Value of Using Multiple Proteases for Large-Scale Mass Spectrometry-Based Proteomics. Journal of Proteome Research, 9(3), 1323-1329. https://doi.org/10.1021/pr900863u 
1085

1086

1087

1088

1089

1090

1091

1092

1093

1094

1095

1096

1097

1098

1099

1100

1101

1102

1103

1104

1105

1106

1107

1108

1109

1110

Tyanova, S., Temu, T., \& Cox, J. (2016). The MaxQuant computational platform for mass spectrometry-based shotgun proteomics. Nature Protocols, 11(12), 2301-2319. https://doi.org/10.1038/nprot.2016.136

Wagih, O., Sugiyama, N., Ishihama, Y., \& Beltrao, P. (2016). Uncovering PhosphorylationBased Specificities through Functional Interaction Networks. Molecular \& Cellular Proteomics, 15(1), 236-245. https://doi.org/10.1074/mcp.M115.052357

Wan, L., de los Santos, T., Zhang, C., Shokat, K., \& Hollingsworth, N. M. (2004). Mek1 Kinase Activity Functions Downstream of RED1 in the Regulation of Meiotic Double Strand Break Repair in Budding Yeast. Molecular Biology of the Cell, 15(1), 11-23. https://doi.org/10.1091/mbc.e03-07-0499

Wickham, H. (2016). ggplot2: Elegant graphics for data analysis (Second edition). Springer. Wickham, H., Averick, M., Bryan, J., Chang, W., McGowan, L., François, R., Grolemund, G., Hayes, A., Henry, L., Hester, J., Kuhn, M., Pedersen, T., Miller, E., Bache, S., Müller, K., Ooms, J., Robinson, D., Seidel, D., Spinu, V., ... Yutani, H. (2019). Welcome to the Tidyverse. Journal of Open Source Software, 4(43), 1686. https://doi.org/10.21105/joss.01686

Wiener, D., Antebi, Y., \& Schwartz, S. (2021). Decoupling of degradation from deadenylation reshapes poly(A) tail length in yeast meiosis. Nature Structural \& Molecular Biology, 28(12), 1038-1049. https://doi.org/10.1038/s41594-021-00694-3

Woo, T.-T., Chuang, C.-N., Higashide, M., Shinohara, A., \& Wang, T.-F. (2020). Dual roles of yeast Rad51 N-terminal domain in repairing DNA double-strand breaks. Nucleic Acids Research, 48(15), 8474-8489. https://doi.org/10.1093/nar/gkaa587

Xie, J., Pierce, M., Gailus-Durner, V., Wagner, M., Winter, E., \& Vershon, A. K. (1999). Sum1 and Hst1 repress middle sporulation-specific gene expression during mitosis in Saccharomyces cerevisiae. The EMBO Journal, 18(22), 6448-6454. https://doi.org/10.1093/emboj/18.22.6448 
1111 Xu, L., Ajimura, M., Padmore, R., Klein, C., \& Kleckner, N. (1995). NDT80, a meiosis-specific gene required for exit from pachytene in Saccharomyces cerevisiae. Molecular and

1114 Yu, G., Wang, L.-G., Han, Y., \& He, Q.-Y. (2012). clusterProfiler: An R Package for Comparing Biological Themes Among Gene Clusters. OMICS: A Journal of Integrative Biology,

1117 Yue, J.-X., Li, J., Aigrain, L., Hallin, J., Persson, K., Oliver, K., Bergström, A., Coupland, P.,

1118 Warringer, J., Lagomarsino, M. C., Fischer, G., Durbin, R., \& Liti, G. (2017). Contrasting 1119 evolutionary genome dynamics between domesticated and wild yeasts. Nature Genetics, 1120 49(6), 913-924. https://doi.org/10.1038/ng.3847

1121 Zhang, Y., Parmigiani, G., \& Johnson, W. E. (2020). ComBat-seq: Batch effect adjustment for 1122 RNA-seq count data. NAR Genomics and Bioinformatics, 2(3), lqaa078. https://doi.org/10.1093/nargab/lqaa078

1124 Zhao, X. (2001). The ribonucleotide reductase inhibitor Sml1 is a new target of the Mec1/Rad53 kinase cascade during growth and in response to DNA damage. The EMBO Journal, 20(13), 3544-3553. https://doi.org/10.1093/emboj/20.13.3544

1127 Zhao, X., \& Rothstein, R. (2002). The Dun1 checkpoint kinase phosphorylates and regulates the ribonucleotide reductase inhibitor Sml1. Proceedings of the National Academy of Sciences, 99(6), 3746-3751. https://doi.org/10.1073/pnas.062502299 
Supplemental Table 1 : Genotypes of the strains used in this study

\begin{tabular}{|c|c|c|c|}
\hline Strain & Genotype & Background & Figure \\
\hline $\mathrm{H} 10355$ & 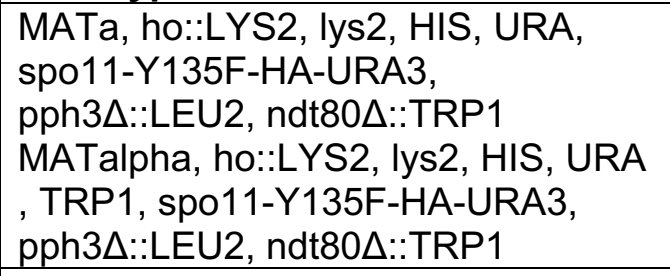 & SK1 & $\begin{array}{l}2 a, 2 b \\
2 d, 4 a, 4 b, 4 e, 5 a, 5 b, 5 c, 5 d, 5 d, \\
\text { S1,S2,S3,S7,S8,S9B,S9C }\end{array}$ \\
\hline H10423 & $\begin{array}{l}\text { MATalpha, ho::LYS2, lys2, HIS, URA, } \\
\text { LEU2, pph3 }:: \text { LEU2, ndt80 } \Delta:: T R P 1 \\
\text { MATa, ho::LYS2, lys2, HIS, URA, } \\
\text { LEU, ndt80 } \Delta:: T R P 1, \text { pph } 3 \Delta:: L E U 2\end{array}$ & SK1 & $\begin{array}{l}2 a, 2 b \\
2 d, 4 a, 4 b, 4 e, 5 a, 5 b, 5 c, 5 d, 5 d \\
\text { S1,S2,S3,S7,S8,S9B,S9C }\end{array}$ \\
\hline H11604 & 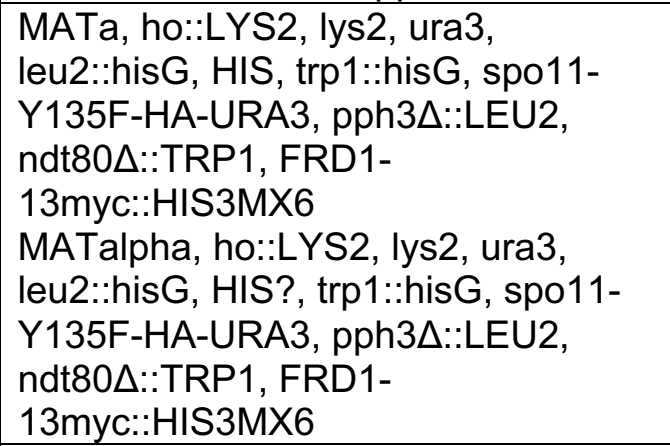 & SK1 & $5 c, 5 d, 5 e, 59 B, 59 c$ \\
\hline $\mathrm{H} 11605$ & 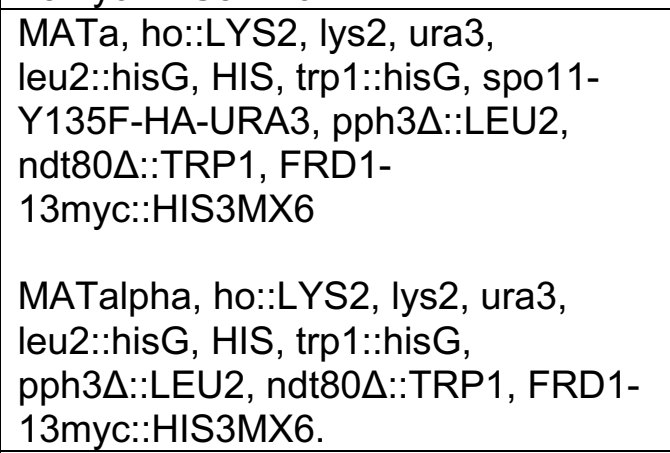 & SK1 & $5 c, 5 d, 5 e, 59 B, 59 C$ \\
\hline $\mathrm{H} 11641$ & 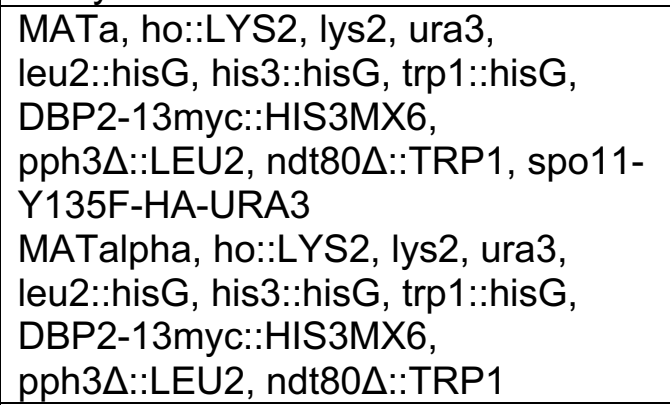 & SK1 & $4 d$ \\
\hline $\mathrm{H} 11642$ & $\begin{array}{l}\text { MATa, ho::LYS2, lys2, ura3, } \\
\text { leu2::hisG, his3::hisG, trp1::hisG, } \\
\text { DBP2-13myc::HIS3MX6, } \\
\text { pph3 } \Delta:: L E U 2, \text { ndt80 }:: \text { TRP1, spo11- } \\
\text { Y135F-HA-URA3 } \\
\text { MATalpha, ho::LYS2, lys2, ura3, }\end{array}$ & SK1 & $4 d$ \\
\hline
\end{tabular}




\begin{tabular}{|c|c|c|c|}
\hline & $\begin{array}{l}\text { leu2::hisG, his3::hisG, his4X, } \\
\text { trp1::hisG, } \\
\text { DBP2-13myc::HIS3MX6, } \\
\text { pph3 } \Delta:: L E U 2, \text { ndt80 } \Delta:: T R P 1, \text { spo11- } \\
\text { Y135F-HA-URA3 }\end{array}$ & & \\
\hline $\mathrm{H} 11746$ & $\begin{array}{l}\text { MATalpha, ho::LYS2, lys2, ura3, } \\
\text { leu2::hisG, his3::hisG, trp1::hisG, } \\
\text { pph3 } \triangle:: L E U 2, \text { spo11-Y135F-HA- } \\
\text { URA3, ndt80 } \triangle:: T R P 1, \text { RNR4- } \\
\text { 13myc::HIS3MX6 } \\
\text { MATa, ho::LYS2, lys2, ura3, } \\
\text { leu2::hisG, his3::hisG, trp1::hisG, } \\
\text { pph3 } \triangle:: L E U 2, \text { spo11-Y135F-HA- } \\
\text { URA3, ndt80 } \triangle:: T R P 1, \text { RNR4- } \\
\text { 13myc::HIS3MX6 }\end{array}$ & SK1 & $5 c, 5 d, 5 e, 59 B, 59 C$ \\
\hline $\mathrm{H} 11747$ & 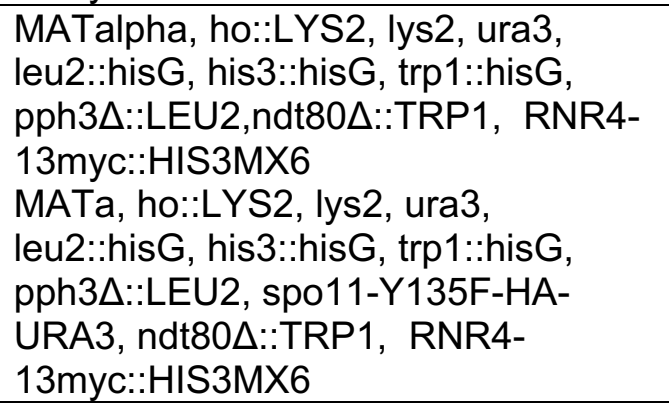 & SK1 & $5 c, 5 d, 5 e, 59 B, 59 C$ \\
\hline $\mathrm{H} 119$ & $\begin{array}{l}\text { MATa, ho::LYS2, lys2, ura3, } \\
\text { leu2::hisG, } \\
\text { MATalpha, ho::LYS2, lys2, ura3, } \\
\text { leu2::hisG, } \\
\text { his4B::LEU2, arg4-Bgl } \\
\text { II } \\
\text { his4X::LEU2 (Bam)-URA3, arg4-Nsp }\end{array}$ & SK1 & 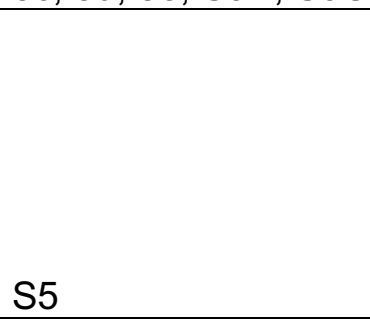 \\
\hline H10963 & $\begin{array}{l}\text { MATa, ho::LYS2, lys2, ura3, } \\
\text { leu2::hisG, his3::hisG, trp1::hisG, } \\
\text { hrr25-2a } \\
\text { MATalpha, ho::LYS2, lys2, URA3, } \\
\text { LEU2, his3::hisG, trp1::hisG, hrr25-2a } \\
\text { 2a } \\
\text { Serine438Alanine } \\
\text { Threonine453Alanine }\end{array}$ & SK1 & S5 \\
\hline 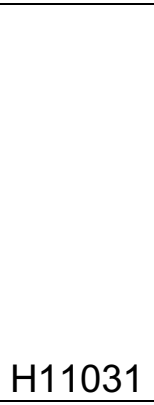 & $\begin{array}{l}\text { MATa, ho::LYS2, lys2, ura3, } \\
\text { leu2::hisG, his3::hisG, trp1::hisG } \\
\text { leu2::pURA3-TetR-GFP::LEU2, } \\
\text { HRR25-13MYC::HIS3MX6 } \\
\text { MATalpha, ho::LYS2, lys2, ura3, } \\
\text { leu2::hisG, his3::hisG, trp1::hisG } \\
\text { leu2::pURA3-TetR-GFP::LEU2, } \\
\text { ura3::TETOx224::URA3, HRR25- } \\
\text { 13MYC::HIS3MX6 }\end{array}$ & SK1 & S5 \\
\hline
\end{tabular}




\begin{tabular}{|c|c|c|c|}
\hline H7797 & $\begin{array}{l}\text { MATa, ho::LYS2, lys2, ura3, } \\
\text { leu2::hisG, his3::hisG, trp1::hisG } \\
\text { MATalpha, ho::LYS2, lys2, URA3, } \\
\text { LEU2, HIS3, TRP1 }\end{array}$ & SK1 & S9A \\
\hline H11368 & $\begin{array}{l}\text { MATa, ho::LYS2, ura3, leu2::hisG, } \\
\text { his3::hisG, trp1::hisG, } \\
\text { MATalpha, ho::LYS2, lys2, } \\
\text { leu2::hisG, HIS, URA3, TRP1, } \\
\text { pph3 } \Delta:: \text { LEU2 } \\
\text { pph3 }:: \text { LEU2 }\end{array}$ & SK1 & S9A \\
\hline H11505 & $\begin{array}{l}\text { MATa, ho::LYS2, lys2, URA3, LEU2, } \\
\text { his3::hisG, trp1::hisG } \\
\text { MATalpha, ho::LYS2, lys2, ura3, } \\
\text { leu2::hisG, HIS3, TRP1 } \\
\text { pCLB2-DBP2::KanMX6 } \\
\text { pCLB2-DBP2::KanMX6 }\end{array}$ & SK1 & S9A \\
\hline $\mathrm{H} 11506$ & $\begin{array}{l}\text { MATa, ho::LYS2, lys2, leu2::hisG, } \\
\text { HIS3, TRP1, ura3, } \\
\text { MATalpha, ho::LYS2, lys2, } \\
\text { leu2::hisG, his3::hisG, trp1::hisG, } \\
\text { URA3, } \\
\text { pph3 }:: \text { LEU2, pCLB2- } \\
\text { DBP2::KanMX6 } \\
\text { pph3 }:: \text { LEU2, pCLB2- } \\
\text { DBP2::KanMX6 }\end{array}$ & SK1 & S9A \\
\hline
\end{tabular}

\section{Supplemental Table $2: \mathrm{m} / \mathrm{z}$ windows used for DIA}

\begin{tabular}{|l|l|l|}
\hline Start & End & Width \\
\hline 350 & 385 & 35 \\
\hline 384 & 412 & 28 \\
\hline 411 & 434 & 23 \\
\hline 613 & 636 & 23 \\
\hline 454 & 474 & 20 \\
\hline 493 & 513 & 20 \\
\hline 552 & 572 & 20 \\
\hline 473 & 494 & 21 \\
\hline 512 & 533 & 21 \\
\hline 532 & 553 & 21 \\
\hline 433 & 455 & 22 \\
\hline 571 & 593 & 22 \\
\hline 592 & 614 & 22 \\
\hline 635 & 659 & 24 \\
\hline
\end{tabular}




\begin{tabular}{|l|l|l|}
\hline 658 & 683 & 25 \\
\hline 682 & 709 & 27 \\
\hline 708 & 738 & 30 \\
\hline 737 & 771 & 34 \\
\hline 770 & 808 & 38 \\
\hline 807 & 848 & 41 \\
\hline 847 & 899 & 52 \\
\hline 898 & 966 & 68 \\
\hline 965 & 1,068 & 103 \\
\hline 1,067 & 1,650 & 583 \\
\hline
\end{tabular}

\section{Supplemental Table 3: DNA break-dependent phosphorylation events}

\begin{tabular}{|l|l|l|}
\hline Protein & Site & Approach for categorization \\
\hline ABD1 & 12 & presence/absence \\
\hline ABF1 & 189 & fold enrichment \\
\hline ABF1 & 193 & fold enrichment \\
\hline ABF1 & 467 & fold enrichment \\
\hline AHP1 & 2 & presence/absence \\
\hline AIM21 & 85 & fold enrichment \\
\hline AKL1 & 12 & presence/absence \\
\hline APC1 & 310 & presence/absence \\
\hline APN1 & 346 & presence/absence \\
\hline ASF1 & 270 & fold enrichment \\
\hline ASF1 & 265 & presence/absence \\
\hline ASG1 & 166 & presence/absence \\
\hline ATG13 & 429 & presence/absence \\
\hline ATG13 & 649 & presence/absence \\
\hline AZF1 & 312 & presence/absence \\
\hline AZF1 & 313 & presence/absence \\
\hline AZF1 & 325 & presence/absence \\
\hline BBC1 & 895 & fold enrichment \\
\hline
\end{tabular}




\begin{tabular}{|l|l|l|}
\hline BBC1 & 894 & fold enrichment \\
\hline BDF1 & 630 & fold enrichment \\
\hline BDF1 & 626 & presence/absence \\
\hline BIR1 & 747 & fold enrichment \\
\hline BIR1 & 381 & fold enrichment \\
\hline BIR1 & 751 & fold enrichment \\
\hline BOI1 & 655 & presence/absence \\
\hline BUB1 & 384 & presence/absence \\
\hline BUD14 & 640 & presence/absence \\
\hline BUD14 & 641 & presence/absence \\
\hline BUD14 & 642 & presence/absence \\
\hline BUD21 & 137 & fold enrichment \\
\hline BYE1 & 210 & fold enrichment \\
\hline CBF1 & 45 & fold enrichment \\
\hline CBF1 & 48 & fold enrichment \\
\hline CDC4 & 53 & presence/absence \\
\hline CHS3 & 538 & fold enrichment \\
\hline CIN5 & 196 & fold enrichment \\
\hline CIN5 & 85 & presence/absence \\
\hline CIN5 & 89 & presence/absence \\
\hline CIN8 & 259 & fold enrichment \\
\hline CIN8 & 261 & fold enrichment \\
\hline CIT2 & 21 & presence/absence \\
\hline CKB2 & 12 & presence/absence \\
\hline CMR1 & 224 & fold enrichment \\
\hline CMR1 & 79 & fold enrichment \\
\hline CUS1 & 104 & presence/absence \\
\hline CYR1 & 241 & presence/absence \\
\hline DAL81 & 17 & fold enrichment \\
\hline DBF4 & 84 & fold enrichment \\
\hline DBF4 & 473 & fold enrichment \\
\hline DBF4 & 496 & presence/absence \\
\hline DBF4 & 501 & presence/absence \\
\hline DBP7 & 56 & presence/absence \\
\hline DCP2 & 686 & fold enrichment \\
\hline DDC1 & 558 & presence/absence \\
\hline DGK1 & 3 & presence/absence \\
\hline DIF1 & 102 & presence/absence \\
\hline DIF1 & 104 & presence/absence \\
\hline DMA2 & 206 & presence/absence \\
\hline DPB4 & 183 & fold enrichment \\
\hline DPS1 & presence/absence \\
\hline DST1 & fold enrichment \\
\hline DUN1 & presence/absence \\
\hline ENT1 15 fobsence \\
\hline ENT1 & \\
\hline
\end{tabular}




\begin{tabular}{|c|c|c|}
\hline ENT2 & 468 & presence/absence \\
\hline ENT2 & 470 & presence/absence \\
\hline ESL1 & 174 & presence/absence \\
\hline EXO1 & 663 & presence/absence \\
\hline EXO1 & 664 & presence/absence \\
\hline FBP1 & 13 & fold enrichment \\
\hline FIN1 & 68 & fold enrichment \\
\hline GAL11 & 789 & presence/absence \\
\hline GCD1 & 296 & presence/absence \\
\hline GCD14 & 302 & fold enrichment \\
\hline GCD14 & 299 & presence/absence \\
\hline GFA1 & 332 & presence/absence \\
\hline GIP2 & 117 & presence/absence \\
\hline GIP2 & 120 & presence/absence \\
\hline GLC7 & 3 & fold enrichment \\
\hline GPA2 & 23 & presence/absence \\
\hline GTT1 & 56 & fold enrichment \\
\hline HAS1 & 12 & fold enrichment \\
\hline HAS1 & 14 & presence/absence \\
\hline HBT1 & 1034 & fold enrichment \\
\hline HBT1 & 1036 & fold enrichment \\
\hline HBT1 & 965 & fold enrichment \\
\hline HED1 & 40 & presence/absence \\
\hline HED1 & 42 & presence/absence \\
\hline HHT1 & 58 & presence/absence \\
\hline HOG1 & 176 & fold enrichment \\
\hline HOP1 & 22 & presence/absence \\
\hline HPC2 & 307 & fold enrichment \\
\hline HPC2 & 388 & presence/absence \\
\hline HRB1 & 27 & fold enrichment \\
\hline HRR25 & 438 & presence/absence \\
\hline HRT1 & 15 & presence/absence \\
\hline HSP12 & 21 & fold enrichment \\
\hline HSP12 & 24 & fold enrichment \\
\hline HSP12 & 59 & fold enrichment \\
\hline HSP26 & 208 & presence/absence \\
\hline HSP26 & 211 & presence/absence \\
\hline HTA1 & 129 & fold enrichment \\
\hline HXT2 & 17 & fold enrichment \\
\hline IGD1 & 64 & fold enrichment \\
\hline IGD1 & 83 & presence/absence \\
\hline IGO2 & 119 & fold enrichment \\
\hline INO1 & 2 & presence/absence \\
\hline IOC2 & 629 & presence/absence \\
\hline IPL1 & 5 & fold enrichment \\
\hline IRR1 & 14 & fold enrichment \\
\hline IRR1 & 12 & fold enrichment \\
\hline IRR1 & 21 & presence/absence \\
\hline IVY1 & 32 & presence/absence \\
\hline
\end{tabular}




\begin{tabular}{|l|l|l|}
\hline LEO1 & 339 & presence/absence \\
\hline MAF1 & 179 & presence/absence \\
\hline MAK21 & 2 & presence/absence \\
\hline MBP1 & 133 & fold enrichment \\
\hline MCM10 & 66 & presence/absence \\
\hline MCM4 & 52 & fold enrichment \\
\hline MDS3 & 621 & fold enrichment \\
\hline MEC3 & 368 & fold enrichment \\
\hline MEC3 & 369 & fold enrichment \\
\hline MEK1 & 486 & presence/absence \\
\hline MEK1 & 356 & presence/absence \\
\hline MET12 & 120 & presence/absence \\
\hline MLH1 & 441 & fold enrichment \\
\hline MMS4 & 2 & fold enrichment \\
\hline MON1 & 130 & fold enrichment \\
\hline MOT1 & 679 & presence/absence \\
\hline MRC1 & 121 & presence/absence \\
\hline MRE11 & 558 & fold enrichment \\
\hline MSC3 & 57 & fold enrichment \\
\hline MSC3 & 64 & fold enrichment \\
\hline MSH6 & 102 & fold enrichment \\
\hline MTL1 & 481 & fold enrichment \\
\hline MTR4 & 84 & fold enrichment \\
\hline NAB2 & 2 & presence/absence \\
\hline NET1 & 1025 & fold enrichment \\
\hline NET1 & 1026 & fold enrichment \\
\hline NET1 & 1024 & fold enrichment \\
\hline NET1 & 440 & presence/absence \\
\hline NET1 & 439 & presence/absence \\
\hline NGG1 & 231 & presence/absence \\
\hline NNK1 & 689 & fold enrichment \\
\hline NOG2 & 60 & fold enrichment \\
\hline NOT3 & 446 & presence/absence \\
\hline NPL3 & 224 & fold enrichment \\
\hline NUP53 & 95 & fold enrichment \\
\hline NUP60 & 10 & fold enrichment \\
\hline NUP60 & 458 & fold enrichment \\
\hline NUP60 & 460 & fold enrichment \\
\hline NUP60 & 483 & presence/absence \\
\hline NUR1 & 441 & presence/absence \\
\hline OLA1 & 67 & presence/absence \\
\hline PAP1 & 550 & fold enrichment \\
\hline PCT1 & fold enrichment \\
\hline PRI 113 & fold enrichment \\
\hline
\end{tabular}




\begin{tabular}{|l|l|l|}
\hline PUP2 & 128 & fold enrichment \\
\hline RAD1 & 40 & fold enrichment \\
\hline RAD14 & 360 & fold enrichment \\
\hline RAD16 & 109 & presence/absence \\
\hline RAD17 & 350 & presence/absence \\
\hline RAD23 & 121 & presence/absence \\
\hline RAD24 & 637 & fold enrichment \\
\hline RAD26 & 27 & presence/absence \\
\hline RAD52 & 205 & presence/absence \\
\hline RAD54 & 132 & presence/absence \\
\hline RAD7 & 64 & fold enrichment \\
\hline RCK2 & 187 & presence/absence \\
\hline RDI1 & 9 & presence/absence \\
\hline REC114 & 55 & fold enrichment \\
\hline RED1 & 483 & fold enrichment \\
\hline RED1 & 484 & fold enrichment \\
\hline RED1 & 486 & fold enrichment \\
\hline RED1 & 473 & fold enrichment \\
\hline RED1 & 517 & fold enrichment \\
\hline RED1 & 518 & fold enrichment \\
\hline RFA2 & 115 & presence/absence \\
\hline RFM1 & 83 & presence/absence \\
\hline RFX1 & 226 & presence/absence \\
\hline RFX1 & 173 & presence/absence \\
\hline RGT1 & 284 & fold enrichment \\
\hline RIF1 & 1362 & fold enrichment \\
\hline RIM15 & 555 & presence/absence \\
\hline RPC53 & 234 & presence/absence \\
\hline RPS16A & 15 & fold enrichment \\
\hline RPS2 & 30 & fold enrichment \\
\hline RPS7B & 14 & presence/absence \\
\hline RRB1 & 5 & fold enrichment \\
\hline RRM3 & 125 & presence/absence \\
\hline RRP12 & 1050 & presence/absence \\
\hline RRP36 & 41 & fold enrichment \\
\hline RRP36 & 42 & fold enrichment \\
\hline RSC9 & 44 & presence/absence \\
\hline RTF1 & 17 & presence/absence \\
\hline RTF1 & 2406 & presence/absence \\
\hline RTG3 & 241 & fold enrichment \\
\hline RTG3 & fold enrichment \\
\hline RTG3 & presence/absence \\
\hline RTG3 & fold enrichment \\
\hline RTT107107 107 folabsence \\
\hline
\end{tabular}




\begin{tabular}{|l|l|l|}
\hline RTT107 & 255 & presence/absence \\
\hline SEC16 & 2139 & presence/absence \\
\hline SEC16 & 2141 & presence/absence \\
\hline SEC3 & 254 & presence/absence \\
\hline SEC3 & 256 & presence/absence \\
\hline SEF1 & 273 & presence/absence \\
\hline SEG1 & 48 & presence/absence \\
\hline SFT2 & 2 & presence/absence \\
\hline SGF73 & 19 & fold enrichment \\
\hline SGF73 & 22 & presence/absence \\
\hline SGO1 & 421 & fold enrichment \\
\hline SGO1 & 423 & fold enrichment \\
\hline SG01 & 426 & fold enrichment \\
\hline SGS1 & 482 & presence/absence \\
\hline SGS1 & 606 & presence/absence \\
\hline SGV1 & 417 & fold enrichment \\
\hline SHP1 & 226 & presence/absence \\
\hline SIR2 & 23 & presence/absence \\
\hline SIR3 & 263 & presence/absence \\
\hline SIR4 & 692 & fold enrichment \\
\hline SIR4 & 342 & presence/absence \\
\hline SKI7 & 88 & fold enrichment \\
\hline SKI7 & 90 & fold enrichment \\
\hline SLD2 & 150 & fold enrichment \\
\hline SLD2 & 151 & fold enrichment \\
\hline SLI15 & 97 & presence/absence \\
\hline SLK19 & 216 & fold enrichment \\
\hline SLM1 & 157 & fold enrichment \\
\hline SLM1 & 158 & fold enrichment \\
\hline SMB1 & 67 & fold enrichment \\
\hline SPC105 & 144 & presence/absence \\
\hline SPC110 & 60 & fold enrichment \\
\hline SPC24 & 2 & presence/absence \\
\hline SPC29 & 230 & fold enrichment \\
\hline SPC29 & 231 & fold enrichment \\
\hline SPC29 & 248 & fold enrichment \\
\hline SPC29 & 249 & fold enrichment \\
\hline SPC29 & 250 & fold enrichment \\
\hline SPG4 & 93 & fold enrichment \\
\hline SPO13 & 139 & fold enrichment \\
\hline SPO13 & fold enrichment \\
\hline SPP1 & presence/absence \\
\hline SPP41 & fold enrichment \\
\hline SPP41 & presence/absence \\
\hline SRP40 & presence/absence \\
\hline SSD1 & \\
\hline SSN2 & 394 & fold enrichment \\
\hline
\end{tabular}




\begin{tabular}{|l|l|l|}
\hline STB3 & 337 & fold enrichment \\
\hline STB3 & 2 & presence/absence \\
\hline STE20 & 192 & presence/absence \\
\hline STE20 & 195 & presence/absence \\
\hline STU1 & 1000 & fold enrichment \\
\hline SUB2 & 2 & fold enrichment \\
\hline SUB2 & 12 & fold enrichment \\
\hline SUB2 & 13 & fold enrichment \\
\hline SUM1 & 722 & fold enrichment \\
\hline SUM1 & 858 & fold enrichment \\
\hline SUM1 & 859 & fold enrichment \\
\hline SWI3 & 88 & fold enrichment \\
\hline SWI3 & 185 & fold enrichment \\
\hline SYH1 & 687 & fold enrichment \\
\hline TAF3 & 345 & fold enrichment \\
\hline TAF3 & 346 & fold enrichment \\
\hline TAF8 & 212 & fold enrichment \\
\hline TAF8 & 215 & fold enrichment \\
\hline TCB3 & 1340 & fold enrichment \\
\hline THO1 & 72 & fold enrichment \\
\hline THO1 & 68 & presence/absence \\
\hline THS1 & 2 & presence/absence \\
\hline TIF4632 & 913 & fold enrichment \\
\hline TIF5 & 184 & presence/absence \\
\hline TOA2 & 102 & presence/absence \\
\hline TOA2 & 95 & presence/absence \\
\hline TOP1 & 24 & fold enrichment \\
\hline TPO3 & 52 & presence/absence \\
\hline TRM10 & 16 & presence/absence \\
\hline TSL1 & 157 & fold enrichment \\
\hline UBC5 & 12 & fold enrichment \\
\hline UBP1 & 776 & fold enrichment \\
\hline UBP13 & 463 & fold enrichment \\
\hline UGX2 & 186 & fold enrichment \\
\hline ULP1 & 264 & fold enrichment \\
\hline ULP1 & 48 & fold enrichment \\
\hline ULP2 & 773 & fold enrichment \\
\hline ULP2 & 929 & fold enrichment \\
\hline ULP2 & 936 & fold enrichment \\
\hline ULP2 & 937 & fold enrichment \\
\hline ULS1 & 204 & fold enrichment \\
\hline UNG1 & 369 & presence/absence \\
\hline USV1 & presence/absence \\
\hline UTP22 & fold enrichment \\
\hline UTP5 & presence/absence \\
\hline VTC2 & XRN1 & presence/absence \\
\hline XRS2 & 1510 absence \\
\hline
\end{tabular}




\begin{tabular}{|l|l|l|}
\hline YBR285W & 117 & presence/absence \\
\hline YCS4 & 495 & presence/absence \\
\hline YDL199C & 61 & fold enrichment \\
\hline YDR090C & 306 & presence/absence \\
\hline YDR090C & 309 & presence/absence \\
\hline YDR239C & 74 & presence/absence \\
\hline YDR239C & 681 & presence/absence \\
\hline YER079W & 10 & presence/absence \\
\hline YER079W & 9 & presence/absence \\
\hline YET1 & 172 & presence/absence \\
\hline YGR130C & 803 & fold enrichment \\
\hline YGR130C & 44 & presence/absence \\
\hline YHR097C & 69 & fold enrichment \\
\hline YJL206C & 90 & presence/absence \\
\hline YLR257W & 238 & presence/absence \\
\hline YPQ2 & 136 & presence/absence \\
\hline ZIP1 & 549 & presence/absence \\
\hline ZIP1 & 75 & presence/absence \\
\hline ZIP1 & 546 & presence/absence \\
\hline ZIP1 & 865 & presence/absence \\
\hline
\end{tabular}

Supplemental Table 4: Phosphosites enriched in spo11-YF

\begin{tabular}{|l|l|l|}
\hline Protein & Site & $\begin{array}{l}\text { Approach for } \\
\text { categorization }\end{array}$ \\
\hline ABF1 & 159 & presence/absence \\
\hline ACF4 & 9 & presence/absence \\
\hline CRZ1 & 453 & presence/absence \\
\hline CUS1 & 114 & presence/absence \\
\hline DNA2 & 17 & fold enrichment \\
\hline DPS1 & 30 & presence/absence \\
\hline IMH1 & 25 & presence/absence \\
\hline KEL1 & 1019 & presence/absence \\
\hline KKQ8 & 113 & presence/absence \\
\hline LIF1 & 261 & presence/absence \\
\hline MLF3 & 145 & presence/absence \\
\hline PDS1 & 212 & presence/absence \\
\hline PDS1 & 213 & presence/absence \\
\hline RPL24A;RPL24B & $83 ; 83$ & presence/absence \\
\hline
\end{tabular}




\begin{tabular}{|c|c|c|}
\hline RPL24A;RPL24B & $86 ; 86$ & presence/absence \\
\hline SEC3 & 301 & presence/absence \\
\hline THO1 & 48 & presence/absence \\
\hline UFD1 & 314 & presence/absence \\
\hline VPS27 & 280 & presence/absence \\
\hline YFR016C & 49 & presence/absence \\
\hline YJL163C & 59 & presence/absence \\
\hline YJL163C & 61 & presence/absence \\
\hline YOL036W & 547 & presence/absence \\
\hline YPL150W & 900 & presence/absence \\
\hline ARG82 & 98 & fold enrichment \\
\hline CKI1 & 54 & fold enrichment \\
\hline GET2 & 60 & fold enrichment \\
\hline PIN4 & 638 & fold enrichment \\
\hline ARO80 & 96 & fold enrichment \\
\hline DNA2 & 236 & fold enrichment \\
\hline DNA2 & 237 & fold enrichment \\
\hline ESC2 & 71 & fold enrichment \\
\hline ESC2 & 73 & fold enrichment \\
\hline ESC2 & 76 & fold enrichment \\
\hline PIB2 & 68 & fold enrichment \\
\hline PIB2 & 70 & fold enrichment \\
\hline REC104 & 110 & fold enrichment \\
\hline $\mathrm{RHO} 4$ & 54 & fold enrichment \\
\hline $\mathrm{RHO} 4$ & 55 & fold enrichment \\
\hline RTT107 & 720 & fold enrichment \\
\hline STU1 & 1113 & fold enrichment \\
\hline UBP1 & 652 & fold enrichment \\
\hline XRS2 & 349 & fold enrichment \\
\hline AVO1 & 144 & presence/absence \\
\hline BNR1 & 621 & presence/absence \\
\hline BUL1 & 195 & presence/absence \\
\hline DRE2 & 212 & presence/absence \\
\hline EDE1 & 1062 & presence/absence \\
\hline FAS2 & 1440 & presence/absence \\
\hline GYP6 & 436 & presence/absence \\
\hline HOP1 & 553 & presence/absence \\
\hline MCM10 & 18 & presence/absence \\
\hline MCM10 & 68 & presence/absence \\
\hline $\mathrm{OSH} 3$ & 447 & presence/absence \\
\hline $\mathrm{OSH} 3$ & 449 & presence/absence \\
\hline $\mathrm{OSH} 3$ & 452 & presence/absence \\
\hline $\mathrm{PKH} 1$ & 303 & presence/absence \\
\hline PXA2 & 776 & presence/absence \\
\hline RAD7 & 118 & presence/absence \\
\hline REC107 & 37 & presence/absence \\
\hline RGA2 & 733 & presence/absence \\
\hline RGC1 & 1033 & presence/absence \\
\hline $\mathrm{RHO} 4$ & 58 & presence/absence \\
\hline
\end{tabular}


bioRxiv preprint doi: https://doi.org/10.1101/2022.02.24.481857; this version posted February 25, 2022. The copyright holder for this preprint (which was not certified by peer review) is the author/funder, who has granted bioRxiv a license to display the preprint in perpetuity. It is made available under aCC-BY-NC-ND 4.0 International license.

\begin{tabular}{|l|l|l|}
\hline RRP9 & 76 & presence/absence \\
\hline SEC16 & 1633 & presence/absence \\
\hline SEC16 & 1634 & presence/absence \\
\hline SEC16 & 1640 & presence/absence \\
\hline SGS1 & 643 & presence/absence \\
\hline SGT1 & 166 & presence/absence \\
\hline SKG3 & 814 & presence/absence \\
\hline SUI2 & 52 & presence/absence \\
\hline SVL3 & 551 & presence/absence \\
\hline SWI3 & 230 & presence/absence \\
\hline SWI3 & 231 & presence/absence \\
\hline SWI3 & 91 & presence/absence \\
\hline TSL1 & 137 & presence/absence \\
\hline VHS3 & 264 & presence/absence \\
\hline VID27 & 417 & presence/absence \\
\hline YAT2 & 848 & presence/absence \\
\hline YEL043W & 895 & presence/absence \\
\hline YPL150W & 807 & presence/absence \\
\hline
\end{tabular}

